\title{
HIV-1 Accessory Protein Vpr: Relevance in the pathogenesis of HIV and potential for therapeutic intervention
}

\author{
Michael Kogan and Jay Rappaport
}

\begin{abstract}
The HIV protein, Vpr, is a multifunctional accessory protein critical for efficient viral infection of target $C D 4^{+} T$ cells and macrophages. Vpr is incorporated into virions and functions to transport the preintegration complex into the nucleus where the process of viral integration into the host genome is completed. This action is particularly important in macrophages, which as a result of their terminal differentiation and non-proliferative status, would be otherwise more refractory to HIV infection. Vpr has several other critical functions including activation of HIV-1 LTR transcription, cell-cycle arrest due to DCAF-1 binding, and both direct and indirect contributions to T-cell dysfunction. The interactions of Vpr with molecular pathways in the context of macrophages, on the other hand, support accumulation of a persistent reservoir of HIV infection in cells of the myeloid lineage. The role of Vpr in the virus life cycle, as well as its effects on immune cells, appears to play an important role in the immune pathogenesis of AIDS and the development of HIV induced end-organ disease. In view of the pivotal functions of Vpr in virus infection, replication, and persistence of infection, this protein represents an attractive target for therapeutic intervention.
\end{abstract}

\section{Introduction}

Human immunodeficiency virus type 1 (HIV-1) is a lentiviral family member that encodes retroviral Gag, Pol, and Env proteins along with six additional accessory proteins, Tat, Rev, Vpu, Vif, Nef, and Vpr. Viral protein $\mathrm{R}(\mathrm{Vpr})$ is a 96 amino acid, $14 \mathrm{kDa}$ protein that was originally isolated almost two decades ago $[1,2]$ and is highly conserved in both HIV-1 and simian immunodeficiency virus (SIV) [3-5]. Numerous investigations over the last 20 years have shown that $\mathrm{Vpr}$ is multifunctional. Vpr mediates many processes that aid HIV-1 infection, evasion of the immune system, and persistence in the host, thus contributing to the morbidity and mortality of acquired immunodeficiency syndrome (AIDS). Vpr molecular functions include nuclear import of viral preintegration complex (PIC), induction of $\mathrm{G}_{2}$ cell cycle arrest, modulation of $\mathrm{T}$-cell apoptosis, transcriptional coactivation of viral and host genes, and regulation of nuclear factor kappa B (NF- $\kappa \mathrm{B})$ activity. The numerous

\footnotetext{
* Correspondence: jayrapp@temple.edu
Department of Neuroscience, Department of Neuroscience, Center for

* Correspondence: jayrapp@temple.edu
Department of Neuroscience, Department of Neuroscience, Center for Neurovirology, Temple University School of Medicine, 3500 North Broad Street, Philadelphia, PA 19140, USA
}

(c) 2011 Kogan and Rappaport; licensee BioMed Central Ltd. This is an Open Access article distributed under the terms of the Creative Commons Attribution License (http://creativecommons.org/licenses/by/2.0), which permits unrestricted use, distribution, and reproduction in any medium, provided the original work is properly cited. functions of $\mathrm{Vpr}$ in the viral life cycle suggest that $\mathrm{Vpr}$ would be an attractive target for therapeutic intervention. A summary of the effects of Vpr on HIV-1 infectivity and permissivness is provided in Figure 1.

\section{Vpr mediates nuclear transport of the HIV-1 pre- integration complex and enables macrophage infection}

In non-dividing mammalian cells, free diffusion of cellular contents into the nucleus is limited to components that are less than $40 \mathrm{kDa}$ [6]. Retroviruses require entry into the nucleus to replicate and are, therefore, naturally restricted to those cells that undergo mitosis. Lentiviruses such as HIV-1, however, are unique among retroviruses in that they able to infect non-dividing cells $[7,8]$. Early studies have shown that the HIV-1 PIC can enter the nucleus by an active process without causing structural damage to the nuclear envelope $[9,10]$. Indeed, Vpr has been found to localize to the nucleus when expressed alone or in the context of viral infection [11-13]. Furthermore, Vpr has been demonstrated to play an important role in the localization of the HIV-1 PIC to the nucleus and a critical role in the infection of 


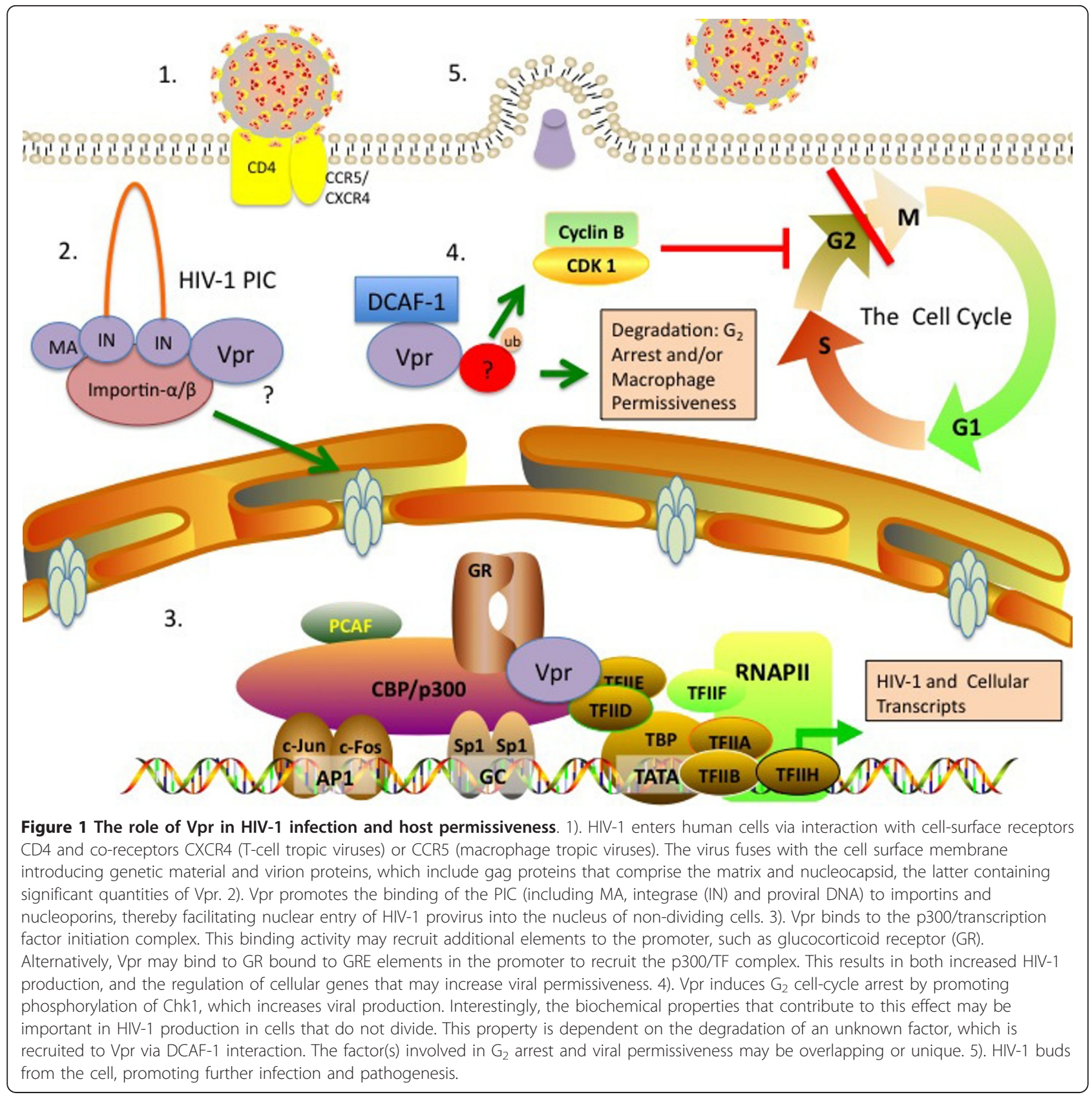

non-dividing cells, as discussed in more detail later in this review. The role of $\mathrm{Vpr}$ in the nuclear import of the PIC is illustrated in Figure 1. The PIC is targeted to the nucleus by $\mathrm{Vpr}$ via interaction with importin- $\alpha$, ultimately promoting binding to nuclear pore proteins.

In addition to $\mathrm{Vpr}$, viral proteins matrix antigen (MA) and integrase (IN), have been shown to participate in nuclear entry. MA and IN both have a functional nuclear localization sequence (NLS) and the nuclear import function of these proteins requires the action of cellular partners importin- $\alpha$ and $-\beta$. Interestingly, it was reported that IN can be sufficient for import of PICs when over expressed in the absence of Vpr or MA [14]. Furthermore, the HIV-1 central DNA flap and capsid protein $(\mathrm{CA})$ have also been reported to play a role in PIC nuclear targeting $[15,16]$. Unlike Vpr, these components appear to promote nuclear localization by a linked mechanism involving the uncoating of the PIC. It appears that there are multiple and sometimes redundant nuclear localization signals involved in nuclear entry of the HIV PIC. Two classical pathways have been characterized for the transport of proteins across the 
nuclear pore complex (NPC): the NLS and M9-dependent pathways (for review see [17]). The former pathway involves the binding of NLS signal containing peptide to importin- $\alpha$ via central armadillo repetitive motifs. Importin- $\alpha$ binds to importin- $\beta$ via an amino-terminal importin- $\beta$-binding (IBB) domain $[18,19]$. The binding of the classical NLS to importin- $\alpha$ is not possible until this IBB binding to importin- $\beta$ occurs, which causes importin- $\alpha$ to expose an internal NLS [19]. This multiprotein structure then interacts with the NPC at which point importin- $\beta$ transports this NLS component into the nucleoplasm.

Two other proteins, GTPase Ran/TC4 and NTF2, are also involved in NLS mediated transport [20-24]. Importin- $\alpha$ serves as an adaptor molecule by bridging NLS containing compounds to nuclear transport machinery. It has been reported, however, that importin- $\alpha$ can facilitate nuclear entry of $\mathrm{Ca}^{2+}$ /calmodulin-dependent protein kinase type IV (CaMKIV) without importin- $\beta$ [25]. Further, importin- $\beta$ can transport cyclin B1/Cdc2 without Ran, suggesting that mechanisms of import exist that can utilize one or both importins [26]. In the M9dependent pathway, transportin facilitates both nuclear import and export of RNA binding protein hnRNP A1 by recognizing an M9 signal sequence [27-31]. M9 mediated nuclear trafficking also depends on the function of Ran/TC4, just as in the classical NLS system [32].

Vpr nuclear localization seems to utilize cellular machinery in a unique way that is independent of the classical NLS and M9 pathways. While viral MA is inhibited by NLS blocking peptides and dominant-negative importin- $\alpha$ (residues 244-529), Vpr nuclear entry is not affected by either treatment strongly supporting the notion that Vpr functions in an NLS-independent manner [14]. Vpr mediated import is also unaffected by treatment with RanQ69L, a dominant-negative form of Ran, that inhibits both M9 and NLS pathways [32-34]. GTP $\gamma$ S, a nonhydrolyzable GTP that inhibits Ran function $[23,35,36]$, has no effect on Vpr localization, further suggesting that Vpr localizes in a non-conventional, Ran-independent manner [37]. Vpr mediated karyophilic activity is starkly contrasted to that of classical SV40 NLS, which requires the presence of importin- $\alpha / \beta$ and Ran GTP[38]. Further, Vpr nuclear localization appears to be independent of energy, or at least requires less energy than conventional transport. Addition of adenosine triphosphate (ATP) or treatment with apyrase, which lowers NTP levels, affected the localization of classical NLS bearing proteins but had no effect on Vpr localization $[34,37]$. Another study suggested that Vpr can enter the nucleus via two different mechanisms; one involving importin- $\alpha$ and another involving energy [39]. In summary, Vpr may use importin- $\alpha$ in a non-conventional, energy independent manner, but may also use a yet undetermined mediator in the absence of importin- $\alpha$ in a process requiring ATP.

In accord with Vpr's ability to promote nuclear localization of the PIC, Vpr has been shown to be essential for productive HIV-1 and HIV-2 infection of macrophages [40-43]. While HIV-1 IN can compensate for loss of Vpr at high MOI of HIV-1 [14,44], other studies suggest that Vpr deficient HIV-1 is non-productive in macrophages at least partly due to the inability to penetrate nuclei of non-dividing mononuclear cells $[38,41,45-50]$. Further, it was shown that Vpr is directly involved in targeting the HIV-1 PIC to the nuclear envelope [51]. It appears that mucosal infection of HIV1 involves the transmission of likely a single virus per patient, as determined by sequence analysis of founder virus [52]. This claim from initial studies has been greatly strengthened by a recent study following patients early during acute infection and the analysis of HIV specific escape epitopes variants by deep sequencing [53]. Therefore, as the multiplicity of infection during transmission is quite low, it would be expected that $\mathrm{Vpr}$ would be required during this event. Later in infection, when viremia is elevated, IN and MA may have appreciable effects on PIC entry, although this remains to be proven. Interestingly, it was also reported that Vpr's nuclear localization and consequent $G_{2}$ arrest properties are important in HIV-1 infection of primary $\mathrm{CD}^{+} \mathrm{T}$ cells irrespective of proliferative status [54](reviewed in: [55]). HIV-1 clearly infects resting T-cells in vivo, where Vpr mediated transport of the PIC into the nucleus would be expected to have importance. The action of $\mathrm{Vpr}$, however, appears to be required for $\mathrm{CD} 4^{+} \mathrm{T}$-cell infection, even under conditions promoting proliferation (i.e. in the presence anti-CD3 and IL-2 treatment [54]). It is likely, therefore, that the transport of the PIC across the nuclear envelope is important in both T-cells and macrophages in vivo.

In addition to Vpr, there are other requirements for viral replication in non-dividing cells. The viral capsid protein, CA, appears to support this role in that mutations in CA disrupt the cell cycle independence of HIV1 infection [56]. The role of CA appears to be independent of nuclear import as one of the mutants in CA exhibited a defect in replication in non-dividing cells beyond the nuclear entry point. The necessity of Vpr's karyophilic properties for the infection of actively dividing cells suggests that the targeting of the PIC to the NPC is a generally required aspect of lentiviral infection, regardless of cell cycle progression. In an evolutionary context, this may imply that lentiviruses evolved to infect non-dividing macrophages and expanded later to $\mathrm{T}$-cells while retaining the use of already evolved infection machinery from the original, non-dividing, target 
cell population. Indeed, macrophages are a common target of all known naturally occurring lentiviruses [57]. Furthermore, T-cell infection is common only to lentiviruses that cause immunodeficiency, further suggesting that these cells were later targets of tropism during lentivirus evolution. In this model, Vpr may contribute to nuclear localization in general, whereas other components, such as CA, may facilitate additional processes necessary for productive infection of cell cycle arrested cells. In conclusion, Vpr seems to be an important mediator of human lentiviral infection, at least in part due to nuclear localization properties. This effect may be most important during periods of low HIV-1 plasma viremia or transmission from person to person.

\section{Correlations between Vpr's structure and nuclear localization function}

Structural studies have been invaluable to understanding HIV-1 viral interaction with host cells, including nondividing macrophages. Relatively recent structural studies have identified three alpha helical domains, $\alpha-\mathrm{H} 1$ (13-33), $\alpha-\mathrm{H} 2$ (38-50), and $\alpha-\mathrm{H} 3(55-77)$ as well as other structural features capable of mediating diverse biological functions [58]. Indeed, Vpr's structure allows for direct binding to many cellular proteins, which likely enables Vpr to mediate functions such as nuclear import and $G_{2}$ arrest. All three alpha helices have been implicated in Vpr mediated nuclear localization [12,13,59-62], while the $G_{2}$ arrest property has been attributed mainly to the $\mathrm{C}$-terminal region of $\mathrm{Vpr}$ [59]. However, as the nuclear import, promoter transactivation, and $\mathrm{G}_{2}$ arrest properties of Vpr seem to not only be related, at least on a structural level, they also may be jointly attributed to specific physiological properties of $\mathrm{Vpr}$ in productive HIV-1 infection of macrophages [63].

Vpr mediates nuclear localization by binding to importin- $\alpha$ via residues located within the alpha helices. While some studies initially reported a low affinity of $\mathrm{Vpr}$ for importin- $\alpha$ [37], others have found that Vpr binds to importin- $\alpha$ using other techniques $[50,51,64] . \mathrm{Vpr} /$ importin- $\alpha$ binding was shown to be non-competitive with that of the classical the NLS found on MA [65]. Kamata and others demonstrated that regions 17-34 $(\alpha \mathrm{H} 1)$ and 46-74 $(\alpha \mathrm{H} 2+\alpha \mathrm{H} 3)$ can both independently localize to the nucleus, albeit to a lower extent than an identified bona fide Vpr NLS consisting of residues 17-74 [66]. Mutations in $\alpha \mathrm{H} 1, \alpha \mathrm{LA}$ (L20,22,23,26A), as well as in $\alpha \mathrm{H} 2+\alpha \mathrm{H} 3, \mathrm{I60P}$ and L69P, completely ablated the ability of the individual peptides to localize to the nucleus. Later, Kamata and others found that Vpr $\alpha \mathrm{H} 1$ and $\alpha \mathrm{H} 3$ both bind importin- $\alpha$, that the IBB domain of importin- $\alpha$ primarily determines this interaction, and that the C-terminal domain of importin- $\alpha$, 393-462, is necessary for nuclear localization of $\mathrm{Vpr}$ [39]. Although, an importin- $\alpha$ lacking an IBB still facilitated import of Vpr, a mutation in Vpr's first alpha helix, $\alpha$ LA, impaired importin- $\alpha$ binding and nuclear localization but still showed perinuclear accumulation. In contrast, a mutation in the third alpha helix, L67P, failed to localize to both the nuclear and perinuclear areas, but still permitted binding to importin- $\alpha$. The authors concluded that binding to importin- $\alpha$ requires only the first alpha helix and that the third alpha helix serves to localize Vpr to the perinuclear area independently of importin binding. Previous findings from other investigators also showed that the use of IBB peptides failed to inhibit Vpr mediated nuclear localization. This suggests that importin- $\alpha$ may be essential for Vpr's karyophilic properties but that the direct interaction between importin- $\alpha$ and Vpr may not be essential [34]. Hitahara-Kasahara and others showed that importin- $\alpha 1, \alpha 3$, and $\alpha 5$ isoforms are all able to induce Vpr mediated nuclear import [38]. Importin- $\alpha$ was shown to be essential for HIV-1 replication in macrophages, suggesting that importin- $\alpha$ nuclear import is a vital process in the infection of these cells. Furthermore, a recent study found that $\mathrm{Vpr}$ does not bind to importin- $\alpha 2$ or importin- $\alpha 2 / \beta 1$ heterodimers, suggesting that cell-line specific expression of importins may regulate Vpr's karyophilic properties [46]. In summary, these studies suggest that importin- $\alpha$ is important for Vprmediated nuclear translocation, but the exact nature of this mechanism is still under investigation.

In addition to the reported binding interaction with importin- $\alpha$, Vpr has been demonstrated to bind directly to nuclear pore proteins $[47,49-51,67]$. Vpr mutants F34I and H71R have been found to lose the ability to localize to perinuclear areas, suggesting that these residues are involved in nuclear pore interaction [50]. These mutants were still found in the nucleus, which is not surprising considering that $\mathrm{Vpr}$ is less than $40 \mathrm{kDa}$. The F34I mutant showed lower binding to importin- $\alpha$ and Nsp1p, a member of the nuclear pore complex. WT Vpr colocalizes with importin- $\beta$ and nuclear pores in perinuclear regions and binds both Pom 121 and very weakly to Nsp1p [47]. An A30P mutant lacked these abilities.

FXFG regions on nucleoporins, a form of phenylalanine-glycine (FG) repeat, have been reported to interact with cytoplasmic proteins involved in nuclear import $[22,68,69]$. Vpr was reported to bind to FXFG containing proteins p54 and p58 as well as to the FXFG region of Nup1 [51]. Further, addition of Vpr was shown to stabilize the binding of importin- $\alpha / \beta$ to Nup1 FXFG. Another report failed to show interaction between $\mathrm{Vpr}$ and FXFG of Pom121, but instead demonstrated that the alpha helices of Vpr interact with hCG1 by binding to a non-FG repeat region located in the $\mathrm{N}$-terminal region on residues 49-170 [67]. This area has no known 
homology to binding motifs and has no known binding partners. In a later study, it was found that four Vpr mutants L23F, K27M, A30L, and F34I, which all occur on one face of the first alpha helix, have impaired hCG1 binding and fail to show nuclear localization [49]. Thus, it seems that Vpr is able to bind to importin- $\alpha$ as well as nucleoporin using the same residues on the first helix. In both cases, there is evidence that Vpr binding to nucleoporin components occurs in a way that is distinct from the classical NLS pathway.

The role of importin- $\beta$ in the nuclear transport of $\mathrm{Vpr}$ is an aspect of the mechanism of Vpr's karyophilic properties that remains to be fully understood. Early studies showed that Vpr fails to bind importin- $\beta$ [65] or that it binds at a low affinity [37]. Oddly, the latter study found greater affinity of Vpr to importin- $\beta$ than to $-\alpha$. Subsequent studies argued that Vpr's localization is importin$\alpha$, but not $-\beta$, dependent. Addition of importin- $\beta$ to digitonin permeabilized cells, which was required for the classical SV40-NLS localization, was unnecessary for Vpr N17C74, a construct containing the minimal region for nuclear localization $[38,66]$. These studies also found that $\triangle \mathrm{IBB}$ importin- $\alpha$, which is unable to bind to importin- $\beta$, still caused nuclear translocation of N17C74. Previous studies demonstrating that the use of IBB peptides failed to inhibit Vpr localization also lend some support to these findings [34]. Further, importin- $\beta$ siRNA failed to prevent $\mathrm{N} 17 \mathrm{C} 74$ localization to the nucleus [38]. Vpr has also been shown to physiologically behave in ways similar to importin- $\beta$, leading some authors to suggest that $\mathrm{Vpr}$ replaces the role of importin- $\beta$, which, like Vpr, also binds to both importin- $\alpha$ and nuclear pores, in the nuclear translocation process [50]. Other studies, however, suggest that importin- $\beta$ is necessary for Vpr's karyophilic properties. Papov and others found that Vpr prevents FXFG Nup 1 peptide mediated dissociation of MA with importin- $\alpha / \beta$ complexes and increases the affinity of importin- $\alpha$ to NLS $[51,65]$. Based on these findings Papov and others proposed that Vpr stabilizes the MA and IN NLS complex with importin- $\alpha / \beta$ to promote nuclear entry. A dominant negative form of importin- $\beta$, residues 71-876 [70] has also been shown to inhibit Vpr localization, further suggesting that importin- $\beta$ plays a role in $\mathrm{Vpr}$ mediated nuclear targeting [34]. Recent studies have clearly shown binding of $\mathrm{Vpr}$ to importin- $\beta 3$, but not to importin- $\beta 1$ or to importin$\alpha 2 / \beta 1$ complexes [46]. This may explain discrepancies in early findings that failed to find effects of isolated importin- $\beta$ which were not necessarily applicable to other importin- $\beta$ isoforms.

The respective roles of the alpha helices and the $\mathrm{C}$ terminal region in nuclear localization and $G_{2}$ arrest remain controversial. Through extensive mutational analysis, Mahalingam and others put forth a hypothesis that the nuclear localization function resides primarily in the alpha helices while the $G_{2}$ arrest property is determined by the carboxyl-terminus [59]. Previous studies lend support to this assertion as the alpha helices, but not $\mathrm{N}$ terminal or C-terminal regions were involved in nucleoporin binding by Vpr [67]. Other reports found that N17C74 Vpr, which lacks the $\mathrm{C}$ and $\mathrm{N}$ terminal regions and other $\mathrm{Vpr}$ constructs lacking the $\mathrm{C}$-terminus are unimpaired in nuclear localization $[11,66]$. Although the C-terminal region closely resembles a classical NLS, this region does not have NLS function and Vpr functions independently of NLS binding [14,71]. Conversely, many other studies found that the C-terminal is necessary or sufficient for nuclear entry of $\mathrm{Vpr}[12,34,47,62,72]$. The discrepancy between these studies remains unexplained. Interestingly, recent studies have shown that all three alpha helices are involved in Vpr oligomerization [63]. The authors reported that mutations that affected oligomerization did not prevent apoptosis induction by $\mathrm{Vpr}$ (a $G_{2}$ arrest dependent property [73]). Nuclear localization, however, was perturbed for these mutants. These studies may suggest that karyophilic and cell cycle arrest properties rely on multiple domains that may be separable to some degree.

\section{Vpr functions as a coactivator of the HIV-1 long terminal repeat}

While Vpr promotes infection of HIV-1 into nondividing cells, the ability of $\mathrm{Vpr}$ to activate both viral and endogenous promoter activity likely contributes to increased viral replication and pathogenesis. Initially, it was observed that $\mathrm{Vpr}$ can reactivate cells latently infected with HIV-1 [74,75]. Later studies demonstrated more specifically that Vpr transactivates the HIV-1 long terminal repeat (LTR) as well as other promoters [76-78]. The U3 region of the HIV-1 LTR has several activating elements, which include NF-AT, glucocorticoid response elements (GRE), NRF, NF- $\kappa \mathrm{B}$, Sp1, a Tat responsive RNA element (TAR), and a TATA box [79-83]. Studies employing HIV-1 LTR indicator constructs demonstrated that $\mathrm{Vpr}$ acts via Sp1 sites [78]. Vpr binds to the Sp1/promoter complex and it has been proposed that Vpr exerts its effects by stabilizing promoter complexes containing multiple bound Sp1 proteins. Other studies, however, support the notion that Vpr transactivates primarily the -278 to -176 region of the LTR, which contains the GREs, while the NF- $\kappa \mathrm{B}$ and Sp1 are utilized by Tat mediated transactivation [84].

Vpr appears to act as a coactivator in the presence of other activating elements but not on a bare promoter alone. Vpr was shown to bind transcription factor IIB (TFIIB), suggesting that the effect of Vpr is indeed due to coactivation rather than direct transcription factor 
function [76]. Vpr has also been demonstrated to potentiate the activation of the HIV-1 LTR by p300 [85] and was shown to form a complex with p300 and TFIIH to cooperatively induce GRE activation in a manner independent of $\mathrm{G}_{2}$ cell cycle arrest [86]. Consistent with these findings, a Vpr mutant deficient in p300 binding, I74,G75A, did not display this property. Several Vpr mutants including R73S, C76S, and Q21P have also been reported to lose HIV-1 LTR transactivation abilities [87]. Intriguingly, the R73S mutation imparted a dominant-negative phenotype with regard to transactivation. Vpr has also been reported to act cooperatively with Tat, another LTR coactivator. Their cooperative effect was disrupted by the Vpr R73S mutation [88]. Therefore, in the presence of $\mathrm{Vpr}$, viral production is likely amplified via coactivation of the HIV-1 LTR by a mechanism that appears to be dependent on multiple binding sites within the viral LTR.

The glucocorticoid receptor (GR) has been a known target of Vpr function for more than a decade [89]. Originally, $\mathrm{Vpr}$ was shown to induce $\mathrm{R}$-interacting protein 1 (Rip-1) nuclear translocation in a GR dependent manner and along with Rip-1 form a complex with GR. A later study showed that Vpr transactivates promoters containing GREs [90]. The authors also reported that Vpr L64A, a mutant for a signature GR binding motif LXXLL, was found to be defective for binding to GR and in GRE transactivation, but like WT Vpr, Vpr L64A retained the ability to bind TFIIB. A Vpr R80A mutant, which lacked $G_{2}$ arrest, was unimpaired in GREmediated transactivation. This study also reported that $\mathrm{Vpr} / \mathrm{p} 300$ synergy was amplified in the presence of dexamethasone. A later publication confirmed many of these observations for LXXLL Vpr mutants in the first and third alpha-helices, 22-26 and 64-68 respectively [91]. The authors reported that mutations in both helices were necessary to completely diminish GRE promoter activation. Subsequently, Kino and others identified Vpr mutants, F72, R73A and I74,G75A, which were unable to bind p300 and were therefore deficient in GRE transactivation [92]. Unlike Vpr L64A, these mutants were not reported to be transdominant, suggesting that Vpr L64A competes with WT Vpr for p300 binding. It is noteworthy that while some subsequent studies have found conflicting results [93], later research has solidified the notion that GR and Vpr function synergistically. Human Vpr interacting protein (hVIP/ Mov34), which binds to both Vpr and GR, translocates to the nucleus following either dexamethasone or $\mathrm{Vpr}$ treatment, further suggesting that Vpr and GR form an functional complex within cells [94]. Vpr and GR also have a gain of function in inhibiting poly (ADP-ribose) polymerase 1 (PARP-1) nuclear translocation, which is a necessary event in NF- $\kappa \mathrm{B}$ transcription [95]. It is worth noting that the effect of $\mathrm{Vpr}$ on NF- $\kappa \mathrm{B}$ remains a controversial topic (discussed below in: "Vpr and immune dysfunction"). However, HIV-1 infection and NF- $\kappa \mathrm{B}$ activation form a positive feedback loop [96,97], and Tat is known to induce the HIV-1 LTR synergistically with $\mathrm{NF}-\kappa \mathrm{B}$ [98], highlighting the importance of the NF- $\kappa \mathrm{B}$ pathway for $\mathrm{HIV}-1$ replication. Considering that NF- $\kappa \mathrm{B}$ signaling is activated during HIV-1 infection, the role of $\mathrm{Vpr}$ in the context of HIV-1 infection may or may not be identical to studies using ectopic Vpr expression. In summary, these studies suggest that Vpr and GR function in a cooperative manner through a mechanism that involves direct binding, and this interaction is at least partly responsible for the transctivation of the HIV-1 LTR by Vpr. The interaction of Vpr with GR and elements of the LTR transcription complex, including p300 is illustrated in Figure 1.

Although Vpr appears to coactivate the HIV-1 promoter via GRE and generally behaves in a GR-dependent manner (with respect to transcriptional activation), the role of glucocortcoids on HIV-1 viral replication remains controversial. Several groups have reported altered hypothalamic-pituitary-adrenal (HPA) axis function in HIV-1 infection [99-104]. Additional in vitro molecular studies have reported that glucocorticoids suppress the HIV-1 LTR [105-109]. Kino and others reported that this effect depends on GR and is not influenced by Vpr [105]. These reports are seemingly in contradiction with aforementioned studies, which showed that Vpr transactivates the HIV-1 LTR and that Vpr enhancement of other promoter elements containing GREs is potentiated by glucocorticoids. Intriguingly, Laurence and others reported that the level of HIV-1 LTR activity in unstimulated cells is not diminished by dexamethasone, while phorbol ester induction of the HIV-1 LTR was attenuated by such treatment [106]. In contrast, some investigators have reported that glucocorticoids have an enhancing effect on HIV-1 LTR activity $[110,111]$. The latter study showed that this effect was seen only in the context of interleukin (IL)-6 and tumor necrosis factor alpha (TNF- $\alpha$ ). Interestingly, a recent study found that extracellular Vpr was capable of increasing IL- 6 production in an NF- $\kappa$ B and C/EBP- $\beta$ dependent manner by stimulating Toll-like receptor 4 (TLR4) signaling in macrophages [112]. Glucocorticoids and TNF- $\alpha$ have also been shown to increase HIV-1 virus production [113]. Therefore, the effect of glucocorticoids on the HIV-1 promoter may be influenced by the presence or absence of pro-inflammatory signals. Increased levels of glucocorticoids have been associated with HIV-1 progression, although some reports suggest that these effects are due to immune system modulation rather than a direct effect on viral replication [12,114-116]. Subsequently, it was shown that RU486, a 
GR and progesterone receptor (PR) inhibitor, can reduce HIV-1 LTR activation by $\mathrm{Vpr}$ and attenuate virus production in X4 infected PBMCs as well as R5 infected macrophages [117]. In contrast, glucocorticoids can increase the permissiveness to infection of unstimulated PBMCs by HIV-1 [118]. These studies demonstrated that the viral life-cycle was blocked at a stage of infection before proviral integration. Interestingly, a similar block in HIV-1 replication was also shown to be abrogated by $\mathrm{Vpr}$, further suggesting GR/Vpr cooperativity [41]. In summary, Vpr may have varying effects on the HIV-1 LTR depending on the context of proinflammatory and anti-inflammatory signals, in addition to GR pathways.

\section{The interrelationship of Vpr functions and their relevance to macrophage permissiveness and HIV-1 reservoirs}

Numerous studies have focused on the role of $\mathrm{Vpr}$ in macrophage infection and permissiveness to HIV-1. However, the involvement of multiple properties of $\mathrm{Vpr}$ in these processes has made it difficult to exactly ascertain which features are most important for macrophage infection. Further, some studies have relied on mutation of individual residues to discern these effects. However, the mutants produced often show defects in multiple properties, which are clearly independent biologically, making the analysis of structural studies challenging. A confusing issue in the literature is that the "so called" $\mathrm{G}_{2}$ arrest function of $\mathrm{Vpr}$, which is likely irrelevant to the status of terminally differentiated cells such as macrophages, has been associated in some studies with HIV-1 infectivity of such differentiated cells. Recent findings in the field, however, suggest the likelihood that both $\mathrm{G}_{2}$ arrest and another, yet unknown, cellular process use similar machinery and that the factors involved in these Vpr functions may have significant overlap.

Findings from mutational studies have suggested overlap in $\mathrm{G}_{2}$ arrest and localization of the HIV PIC to the nucleus. In a recent study the authors reported that the $\mathrm{G}_{2}$ arrest properties of $\mathrm{Vpr}$ depend on nuclear localization [49]. Jacquot and others showed that four $\mathrm{Vpr}$ mutations in the first alpha helix, Vpr L23F, K27M, A30L and F34I all exhibit both at least partially impaired $G_{2}$ arrest and defective nuclear localization while Vpr mutants R80A and R90K were deficient in $G_{2}$ arrest alone. While previous studies confirmed some of these results, they have also reported opposite results for the same mutations or support the notion that the two properties are independent $[11,50,59]$. It is noteworthy to mention that these two properties are completely separated in $\mathrm{HIV}-2 / \mathrm{SIV}_{\mathrm{SM}}$ viruses which accomplish nuclear localization by using accessory protein $\mathrm{Vpx}$ and $\mathrm{G}_{2}$ arrest by using $\mathrm{Vpr}$ [119]. $\mathrm{Vpr} / \mathrm{Vpx}$ defective SIV virus, but not viruses defective in either protein alone, have been shown to have a greatly attenuated course with no progression to AIDS in rhesus monkeys, suggesting that both of these properties play significant roles in vivo [120]. Many studies also argue that nuclear localization rather than $G_{2}$ arrest is important in macrophage infection of HIV-1. For example, HIV-1 transcripts in Vpr defective viruses lose the ability to be detected at some time between the reverse transcription and pro-viral DNA replication phases [41], suggesting that in the absence of $\mathrm{Vpr}$ the viral life cycle may be inhibited at the nuclear entry phase. The ability of IN to compensate for Vpr loss also suggests that nuclear localization plays a predominant role $[14,44]$. Therefore, there is ample evidence to support the notion that Vpr can induce nuclear localization independent of $\mathrm{G}_{2}$ arrest. Mutation studies have not demonstrated such independence, however, as the structure/function relationships have not proven separable.

As nuclear localization and $\mathrm{G}_{2}$ arrest seem to be related in some structural studies, it is not surprising that both properties of $\mathrm{Vpr}$ have been linked to productive infection of macrophages. Subbramanian and others argued that Vpr's ability to cause $\mathrm{G}_{2}$ arrest may also play a role in HIV-1 infection of macrophages [121]. Upon infecting macrophages with HIV-1 viruses that were Vpr WT, ATG-Vpr (Vpr negative), Vpr R62P (impaired in nuclear localization), and $\mathrm{Vpr}$ R80A (impaired in $G_{2}$ arrest), the authors observed that unlike the Vpr R62P mutant, which only inhibited viral growth at low MOI, the Vpr R80A and ATG-Vpr viruses were the most impaired at higher MOI. However, R80A mutant, as expected, showed no differences as compared to the other mutants in the number of $G_{2}$ stage cells in terminally differentiated macrophages, as these cells are already arrested. These results suggest that the so called $\mathrm{G}_{2}$ arrest property of $\mathrm{Vpr}$ is important in different ways than nuclear localization for productive viral infection in myeloid cells. While the authors hypothesized that the effect of $G_{2}$ arrest on viral replication is due to biochemical properties of the mutant protein, the independence of these two properties in mutated Vpr constructs remains to be fully ascertained.

It is very important to note that the $G_{2}$ arrest property of $\mathrm{Vpr}$ has been recently attributed binding to damaged DNA binding protein 1 and Cullin 4a-associated factor1 (DCAF-1) [122-128] (originally identified as a binding partner called VprBP [129]), and is a result of subsequent induction of ataxia telangiectasia-mutated and Rad3 related (ATR) kinase. While it is unknown how Vpr/DCAF-1 binding promotes $\mathrm{G}_{2}$ arrest, it has been proposed that Vpr may recruit a particular factor to this complex, promoting ubiquitination and degradation of a yet unknown cellular protein or, perhaps, several targets 
$[130,131]$. Macrophages are non-dividing cells and are therefore not subject to the cell-cycle arrest function of $\mathrm{Vpr}$ and even lack the prerequisite ATR induction in the presence of $\mathrm{Vpr}$ [132]. The findings that demonstrate the importance of $\mathrm{Vpr}$ residues involved in $\mathrm{G}_{2}$ arrest in promoting HIV-1 replication likely suggest that the recruitment of native cellular factors to DCAF-1 promotes both properties. However, it is unknown what binding partners mediate these effects or if they are the same or overlapping for both $G_{2}$ arrest and cellular permissiveness. A synopsis of these three properties and their effects on HIV-1 infection of macrophages is found in Figure 1.

The $\mathrm{G}_{2}$ arrest and HIV LTR promoter transactivation properties of Vpr may also be dependent or independent of each other. Many studies have shown that Vpr's ability to cause $G_{2}$ arrest and increase viral production are linked $[62,75,85,133,134]$. While $\mathrm{G}_{2}$ cell cycle arrest may make HIV-1 infected T-cells and oddly macrophages, which are not dividing, more permissive to active infection, many studies have shown that Vpr constructs deficient in $G_{2}$ arrest maintain the ability to function as a coactivator [59,84,90-92]. While $\mathrm{G}_{2}$ arrest and transactivation properties of $\mathrm{Vpr}$ both impart positive effects on viral replication, whether these effects represent independent functions is a matter of debate.

As mentioned previously, $\mathrm{Vpr}$ is believed to allow for permissive infection of HIV-1 in many cell types, but is considered particularly important for the infection of non-dividing cells such as macrophages and resting $\mathrm{T}$ cells. As such, Vpr is likely important in generating a long lived reservoir for virus infection. Indeed, it has been suggested based on results in non-human primate studies, that macrophages are likely the main producers of virus in late stage simian/human immunodeficiency virus (SHIV) at a time when $\mathrm{CD}^{+}{ }^{+} \mathrm{T}$-cells have been depleted [135]. In HIV-2/SIV $\mathrm{SM}_{\text {virus, }} \mathrm{Vpr}$ is hypothesized to have duplicated, giving rise to $\mathrm{Vpx}[5,136]$. Vpr and $\mathrm{Vpx}$ have discrete functions in $\mathrm{HIV}-2 / \mathrm{SIV}_{\mathrm{SM}}$ viruses causing $\mathrm{G}_{2}$ arrest and nuclear localization respectively, whereas Vpr has both properties in HIV-1 [119]. Recently, it was shown that SIV/HIV-2 Vpx overcomes a block to reverse transcription in macrophages, further suggesting that HIV-1 Vpr may increase viral permissiveness in myeloid cells as well [137-139]. It is noteworthy to mention that $\mathrm{Vpx}$ also has such an effect on HIV-1 defective in Vpr, yet this effect is not seen with Vpr treatment. This likely suggests that Vpx acts on cellular targets that may be only partially in common to those of Vpr. Interestingly, Vpx binds DCAF-1 in a way similar to Vpr [125] and such interaction is necessary for the permissive effects described above. It has been suggested that Vpr and Vpx compete for binding to this complex and perhaps recruit unique or only partly overlapping binding partners [130]. Therefore, it is likely that the particular macrophage restriction factor antagonized by $\mathrm{Vpx}$ is not a target of Vpr. In agreement with this notion, previous studies have attributed Vpr to lifting a post-reverse transcriptional block, whereas Vpx seems to affect an earlier block in viral replication [41]. However, Vpr may use the same system to recruit other factors that promote permissive infection of HIV-1 into macrophages. It is unknown why HIV-1 Vpr does not possess the same properties as seen with Vpx in SIV or HIV-2, but obviously HIV-1 does not rely on these effects for successful infection in vivo. Considering that Vpr has small effects on macrophage permissiveness to HIV-1 during single a round of infection [140], but causes profound changes after long-term culture [40,41], it is likely $\mathrm{Vpr}$ mediated macrophage permissiveness has not been detected as compared to Vpx simply due to the a smaller magnitude of it's effect or due to shortterm culture conditions.

HIV-1 virus is known to have anti-apoptotic properties in chronically infected macrophages and microglia [141], and causes a reduction of pro-apoptotic Bax expression in mitochondria of persistently infected cells [142]. While Vpr promotes apoptosis [143,144], it also exhibits anti-apoptotic properties [145]. It is noteworthy to mention that no study of which we are aware has ever shown toxicity of $\mathrm{Vpr}$ in macrophages. On the contrary, it has been argued that macrophages lack the ATR mediated the cell stress response normally induced by $\operatorname{Vpr}$ [132], which is required for the apoptotic activity that has been reported in other cell types. Intriguingly, Vpr was observed to inhibit apoptosis in a lymphoblastoid cell line by inducing Bcl-2, with concomitant downregulation of Bax in a manner seemingly contingent on Vpr expression level [145]. Further, Vpr mediates resistance to cell death from Fas ligand and TNF- $\alpha$ in these cells. The $\mathrm{G}_{2}$ arrest function of Vpr in these cells, however, is most likely defective since these clones exhibited cell cycle characteristics similar to those of controltransfected cells. As Vpr is toxic to non-myeloid cells, such as T-cells, the possible anti-apoptotic effects of $\mathrm{Vpr}$ that have been observed and attributed to Vpr in the study may be due to a low level of Vpr expression in the cell lines used. As such, the pro-survival effects of Vpr may need to be evaluated further. If Vpr promotes cell survival, it is conceivable that the pro-survival effects of HIV-1 may involve the action of Vpr, especially in macrophages, possibly in combination with additional host-viral interaction. In combination with the aforementioned abilities of $\mathrm{Vpr}$ to increase viral replication by inducing $G_{2}$ arrest and activating the HIV-1 LTR, the potential of Vpr to promote infection of and survival of macrophages could be a highly significant factor in the development and/or maintenance of 
macrophage viral reservoirs. The differential mechanism of pro-apoptotic/anti-apoptotic Vpr activity warrants further investigation and may provide an avenue of therapy as an additive to highly active antiretroviral therapy (HAART), now renamed combination antiretroviral therapy (cART).

\section{Vpr and HIV dementia}

HIV encephalopathy (HIV-E) is an associated underlying pathological condition seen in autopsy of patients with HIV-1 associated dementia (HIV-D), a disease characterized by motor and cognitive deficits. The presence HIV-1 virus in the brain is seemingly the cause of this condition as it was detected by in situ hybridization in patients with HIV-E but not in HIV-1 patents who do not exhibit this pathological condition [146]. Although the introduction of cART initially reduced the prevalence of HIV-D, the prevalence of HIV associated neurocognitive disorders (HAND) has been increasing (for review see [147]). While it is unclear if the minor and severe forms of HAND have common etiologic mechanisms, there is reason to suspect the importance of HIV infection in macrophages in the central nervous system (CNS) and/or the periphery, as well as the role of Vpr. Since Vpr has been implicated as both a direct and indirect contributor to the development of dementia, Vpr may also play a role in the more subtle forms of neurologic disease (Figure 2).

Although the principle mechanism of HIV-D pathology is not known, there is a preponderance of evidence suggesting that mononuclear cells play a critical role in disease progression. The major sources of HIV-1 production in the brain appear to be macrophages and microglia [146,148-150]. Furthermore, in brains of animals infected with SIV, perivascular macrophages are responsible for the majority of virus production, further implicating these cells in the pathology of CNS disease [151]. Macrophage/microglia numbers are more highly correlated with the severity of HIV-D than the presence of HIV in the CNS [152]. Patients with HIV-D also have

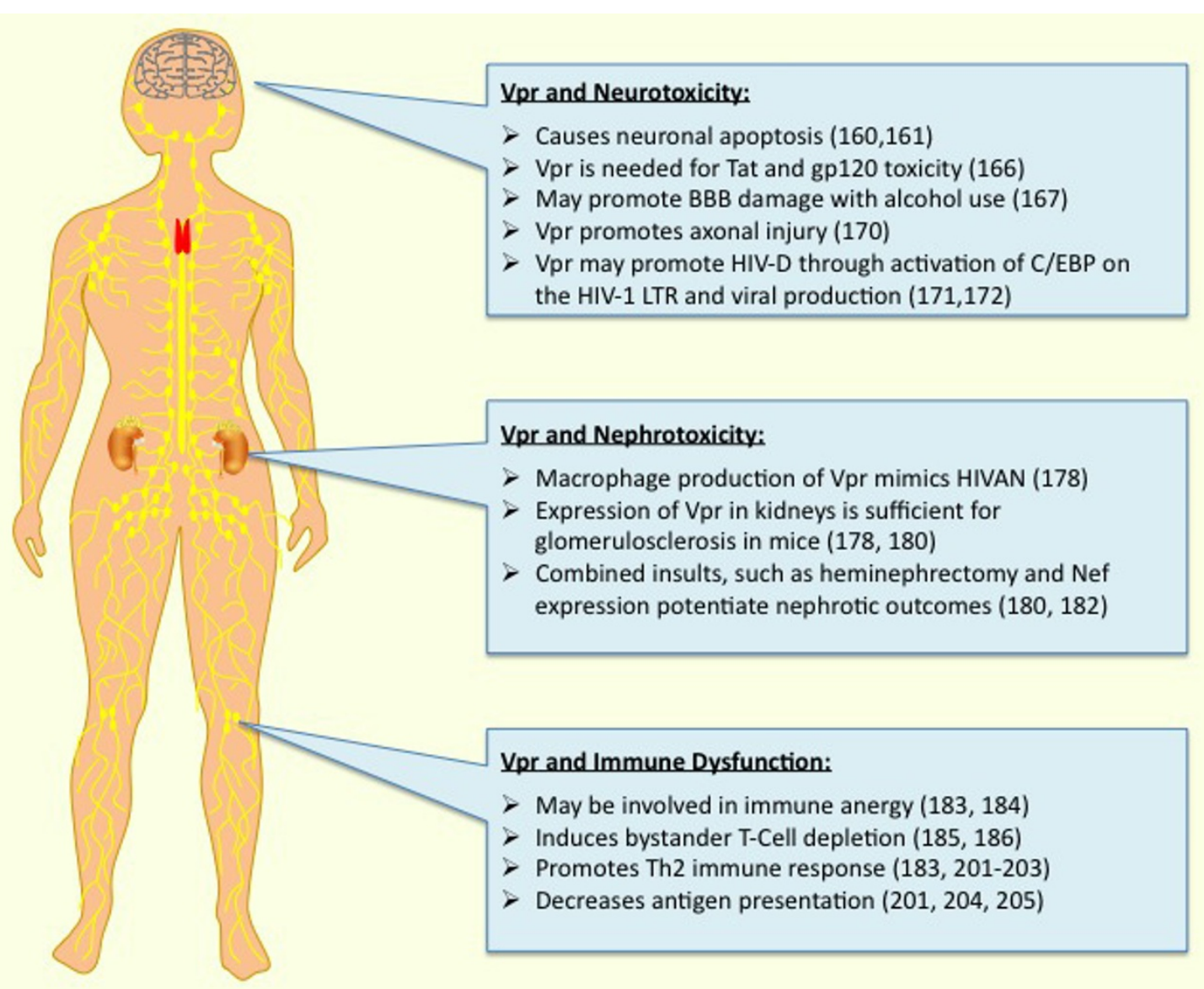

Figure 2 Summary of HIV-1 pathology involving Vpr. Vpr is likely important for both immune dysfunction as seen in AIDS and associated diseases including HIV-D and HIVAN. 
elevated numbers of $\mathrm{CD} 14^{+} / \mathrm{CD} 16^{+}$monocytes in the periphery $[153,154]$, which have neurotoxic properties in vitro [154]. CD14 ${ }^{+} / \mathrm{CD} 16^{+}$, HIV-1 positive macrophages have also been found in brains of patients suffering from HIV-D [155]. The presence of TNF-a protein and mRNA in patients with HIV-D has been reported to significantly correlate with the severity of symptoms in these patients, further suggesting that activated macrophage activity is directly involved in HIV-D pathology $[152,156]$. The increased number of CNS macrophages/ microglia (in the absence of evidence for proliferation) suggests that the accumulation of myeloid cells in the brain is due to trafficking of peripherally derived macrophages [157], (reviewed in [158]). As mentioned previously, $\mathrm{Vpr}$ plays a significant role in the permissive infection of HIV-1 into macrophages and may increase the survival of infected myeloid cells; therefore, it is indirectly related to HIV-D pathogenesis.

Vpr may be a direct effector of HIV-1 mediated HIVE pathology. Higher levels of Vpr have been found in the CSF of patients with HIV associated cognitive deficits. Vpr has been detected by immunofluorescence in the basal ganglia and frontal cortex of brains with HIV$E$ and is elevated in the serum and CSF of seropositive HIV patients $[74,159]$ and has been shown to cause apoptosis in vitro [160]. The cells that contained Vpr in HIV-E brains were either macrophages or neurons. Transgenic mice that express $\mathrm{Vpr}$ in monocytoid cells display neuronal injury in the basal ganglia and subcortical area, which confirms in vitro findings [161]. Mechanistically, the neurotoxic effect of Vpr depends on the 70-96 C-terminal region, which is essential for the induction of neuronal apoptosis in striatal and cortical cells [162]. In neurons, this effect is mediated by activation of p53, caspase 9, and caspase $8[161,163]$. Although gp120 and Tat have also been shown to induce apoptosis in neuronal cells $[164,165]$, intracellular Vpr expression in NT2 cells seemed to be necessary for the induction of apoptosis [166]. This effect many have even greater clinical relevance considering that $\mathrm{Vpr}$ and ethanol together cooperatively increase apoptosis in brain microvascular endothelial cells, which may possibly allow for greater blood brain barrier permeability to virus and infected cells [167]. Most recently, Vpr was shown to increase reactive oxygen species production in microglia and neuroblastoma cell lines, to lower ATP, to lower plasma membrane $\mathrm{Ca}^{2+}$ ATPase (PMCA) protein levels, and increase cytoplasmic permeability in neuroblastoma cells [168]. By lowering PMCA levels, the efflux of $\mathrm{Ca}^{2+}$ would be expected to increase in neuronal cells, which has been linked to cell death signaling in these cells (for review see [169]). Vpr produced from HIV-1 infected macrophages was found to impair axonal growth of neuronal precursors independently of apoptosis [170]. Vpr binds to CCAAT-enhancer binding protein (C/EBP) sites on the HIV-1 LTR [171] and consequently a C/EBP site with high affinity for $\mathrm{Vpr}$, C/EBP $\mathrm{I}$, is associated with clinical progression to HIV-D [172]. It has been proposed that Vpr activates C/EBP sites by direct binding to C/EBP I in the HIV-1 LTR, which has low affinity for $\mathrm{C} / \mathrm{EBP}$, as well as indirectly by upregulating the expression of C/EBP in host cells [173]. Vpr and Nef both induce RANTES/CCL5 chemokine in microglia, causing activation of brain mononuclear cells, which correlates with clinical dementia [174]. Therefore, $\mathrm{Vpr}$ is a direct and indirect mediator of cell death and neuronal impairment in HIV-1 patients as well as a necessary factor for the infection and survival of HIV infected macrophages, thereby further contributing to the pathogenesis of HIV-D.

\section{Vpr and HIVAN}

HIV associated nephropathy (HIVAN) is a form of collapsing focal segmental glomerulosclerosis, largely due to HIV-1 protein toxicity to epithelial cells (for review see [175]). The most significant incidence of the disease is seen in HIV-1 positive patients of African descent, likely due to a prevalence of the MYH9 allele in this population [176]. As in HIV-D, macrophage trafficking and expression of virus has been implicated in pathology of HIVAN. Fibroblast growth factor 2 (FGF-2), which is elevated in kidneys of children with HIVAN, increases the attachment of uninfected and HIV-1 infected PBMC to tissue culture plates coated with renal tubular epithelium [177]. In vivo, FGF-2 likely increases the invasion of inflammatory cells into renal tissue, leading to renal injury. Interestingly, $\mathrm{Vpr}$ has been implicated in the development of HIVAN (Figure 2). A c-fms/Vpr transgene in mice produced focal glomerulosclerosis, suggesting that macrophage specific Vpr expression might be sufficient for kidney damage [178]. Further, it was reported that FVB/N mice expressing Vif, Vpr, Nef, Tat, and Rev in podocytes developed nephropathy and proteinuria suggesting that viral proteins themselves have toxic effects in the kidneys [179]. Vpr expressed in a transgenic mouse model demonstrated that presence of $\mathrm{Vpr}$ in podocytes is sufficient for glomerulosclerosis [180]. Lentiviral experiments in vitro produced similar findings [181]. Vpr expression in combination with Nef, however, results in severe kidney damage in transgenic mice [180]. Vpr expression combined with heminephrectomy also resulted in far more profound nephrotic changes [182]. The impact of heminephrectomy was almost entirely prevented by including treatment with angiotensin II type 1 (AT1R) receptor blocker olmesar$\tan$. To date, however, no specific therapies targeting $\mathrm{Vpr} / \mathrm{Nef}$ nephrotoxicity or the attachment of affected macrophages to the tubular epithelium have been 
developed. It should be noted that in the studies using single or combined expression of viral proteins in particular cell types, such as in macrophages in the c-fms driven Vpr model, it is unclear if these effects occurred due to the secretion of these products from cells trafficking to the kidneys or due to other inflammatory cytokines produced in these cells due to the expression of these products.

\section{Vpr and immune dysfunction}

Vpr has profound inhibitory effects on many members of the immune system involved in adaptive response (Figure 2). Consequently, Vpr reduces the efficacy of DNA and SIV-Nef vaccination in vivo, suggesting that Vpr may aid in evasion of immune response during HIV-1 [183,184]. The mechanism of immune dysfunction caused by Vpr appears to involve the induction of apoptosis and cell cycle arrest in bystander T-cells, contributing to the depletion of immune cells. While $\mathrm{Vpr}$ is seemingly anti-apoptotic in HIV-1 infected cell lines, in vitro studies suggest that bystander T-cells may be induced to undergo apoptosis in response to extracellular or secreted Vpr $[145,185,186]$. Although many studies argue that Vpr has effects outside of the infected cell due to secretion, this point remains controversial. However, in vivo, Vpr alone has been shown to be contribute to HIV-1 mediated immune dysfunction by promoting depletion of thymic cells (reviewed in [187]). Activation induced cell death by apoptosis has been proposed as a mechanism of HIV-1 infected $\mathrm{CD}^{+}{ }^{+}$lymphocyte depletion, although multiple mechanisms distinct from Vpr likely contribute to this process $[188,189]$. Vpr can increase Fas dependent caspase- 8 dependent cleavage in T-cells to induce apoptosis, providing a potential mechanism for increased cell death. CD4 promoter-Vpr transgenic mice do show Tcell depletion in a Bcl-x, Bax, and caspase-1 dependent and Fas-Fas ligand independent manner [190]. $G_{2}$ arrest precedes the induction of apoptosis by $\mathrm{Vpr}$ and has been reported to be necessary for progression to apoptosis [73], however, the latter findings remain controversial [191]. Recently, it was demonstrated that this property depends on Vpr activated phosphorylation of Chk1, an event that begins during the $\mathrm{S}$ phase of the cell cycle [192]. Apoptosis occurs via caspase-9 and seems to cause apoptosis in cancer cell lines with mutated p53, suggesting that this effect is independent of p53 function [193-195]. Vpr has also been postulated to increase the expression of TNF- $\alpha$ in dendritic cells (DC)s and in this way may indirectly promote apoptosis in CD8 ${ }^{+}$T-cells [196]. The Vpr mediated depletion of uninfected $\mathrm{T}$-cell populations likely contributes, in part, to the immune dysfunction observed in AIDS.
Recent studies have identified additional mechanisms of Vpr mediated T-Cell depletion. Vpr has been shown to upregulate natural killer group 2, member D (NKG2D) ligands in $\mathrm{CD}^{+}$lymphocytes, which resulted in natural killer (NK) mediated toxicity to these cells $[197,198]$. It is unclear what effect Vpr has on HIV-1 infected $\mathrm{CD}_{4}^{+} \mathrm{T}$-cell depletion in vivo, since Vpr alone is sufficient to upregulate NKG2D ligand expression. Vpr could induce bystander T-cell killing due to NK mediated toxicity. It should also be mentioned, however, that Vpr has been reported to inhibit NK function $[199,200]$, which would be predicted to oppose NK mediated toxicity. If infected T-cells are depleted due to NK function, this may suggest that the infection of these targets is outweighed by the advantage conveyed by immune suppression. Interestingly, the upregulation of NKG2 ligands by Vpr is also related to DCAF-1 binding in an ATR related mechanism, which suggests that these ligands may not be readily upregulated in macrophages that are reported to lack ATR response to Vpr expression $[132,197,198]$. Considering that macrophages have been reported to be the main viral reservoir during late stage infection of rhesus macaques with an SIV/ HIV-1 chimeric virus (SHIV) [135], the depletion of Tcells may not be a limitation to virus persistence due to the availability of myeloid target cells. In summary, Vpr has been reported to cause apoptosis of bystander Tcells by multiple mechanisms, which may contribute to decreased immune function and possibly impaired viral clearance in the host.

Vpr may suppress cellular immunity by modulating antigen mediated activation and cytotoxic killing of surviving $\mathrm{T}$-cells. In vivo, $\mathrm{Vpr}$ promotes a shift toward a Th2 response, likely by suppressing IFN- $\gamma$, a Th1 inducing cytokine [183]. Other studies have also confirmed that Vpr promotes Th2 cytokine IL-10 while suppressing the expression of Th1 cytokine IL-12 [201-203], presumably by modulating NF- $\kappa \mathrm{B}$ response (discussed below). T-cell function also may be perturbed by downregulation of CD28 and CTLA- 4 which are required for activation by antigen presenting cells and therefore adaptive immune function [204]. Recombinant Vpr has been shown to lower activation of macrophages and maturation of DCs by inhibiting the expression of key co-stimulatory molecules including CD40, CD80, CD83, and CD86 [201,205]. This suggests that Vpr may dampen antigen presentation by downregulation of partner molecules on both presenter and effector cells. Vpr has also been shown to suppress immune activation to superantigens in vivo [206]. More recently, Vpr has also been shown to modulate NK cell function, causing a reduction in cytolytic killing and differential regulation of IL-12 and TGF- $\beta$ by Smad3 activation [200]. Therefore, Vpr may significantly contribute to the immune 
deficiency seen in AIDS by altering both adaptive and innate immune cellular function.

Evidence from many studies suggests that Vpr's effect on the immune system seems to be mediated by interaction with the NF- $\kappa$ B pathway by a mechanism involving GR. Glucocorticoids have been shown to have immunosuppressive effects due to NF- $\kappa \mathrm{B}$ inhibition and induction of I kappa B alpha ( $\mathrm{I} \kappa \mathrm{B} \alpha)$, which prevents NF- $\kappa \mathrm{B}$ translocation into the nucleus thereby preventing cytokine release and immune activation [207,208]. Vpr was first shown to induce T-cell apoptosis in a TCR dependent mechanism by inducing $\mathrm{I} \kappa \mathrm{B}$ and reducing NF- $\kappa \mathrm{B}$ activity [209]. Vpr downregulates NF- $\kappa$ B inducible cytokines, including IL-2, IL-12, TNF- $\alpha$, and IL-4, and chemokines, MIP-1 $\alpha$, MIP-1 $\beta$, and RANTES [209-211]. These effects were reversed with RU486 treatment, suggesting that the inhibition of NF- $\kappa \mathrm{B}$ via $\mathrm{I} \kappa \mathrm{B}$ induction mechanistically involves GR. Indeed, Vpr and GR cooperate to suppress NF- $\kappa$ B mediated transcription [95]. The cooperativity of $\mathrm{Vpr}$ with GR has been proposed as a cause of the hypersensitivity to glucocorticoids seen in
HIV infected patients thus amplifying the GR induced immunosuppressive effect [210]. Recent studies, however, have reported that Vpr can increase NF- $\kappa \mathrm{B}$ activity by inducing $\mathrm{I} \kappa \mathrm{B}$ phosphorylation and subsequent degradation [112]. Indeed, other studies have also shown that Vpr can induce NF- $\kappa$ B activity [212,213], therefore, the context in which these effects differ remains to be elucidated. Vpr's effects on the immune system seem to be carried out by several and possibly independent mechanisms. Therapeutic strategies targeting Vpr, therefore, may impair virus replication directly and at the same time serve promote functional antiviral immune responses.

\section{Targeting Vpr's effects as an adjuvant therapy to CART for HIV}

The actions of Vpr in the virus life cycle and its role in the pathogenesis of HIV induced immune dysfunction and end-stage organ disease suggest the potential importance of $\mathrm{Vpr}$ as a therapeutic target for the treatment of HIV infection (Figure 3). Several additional key observations have provided additional support for

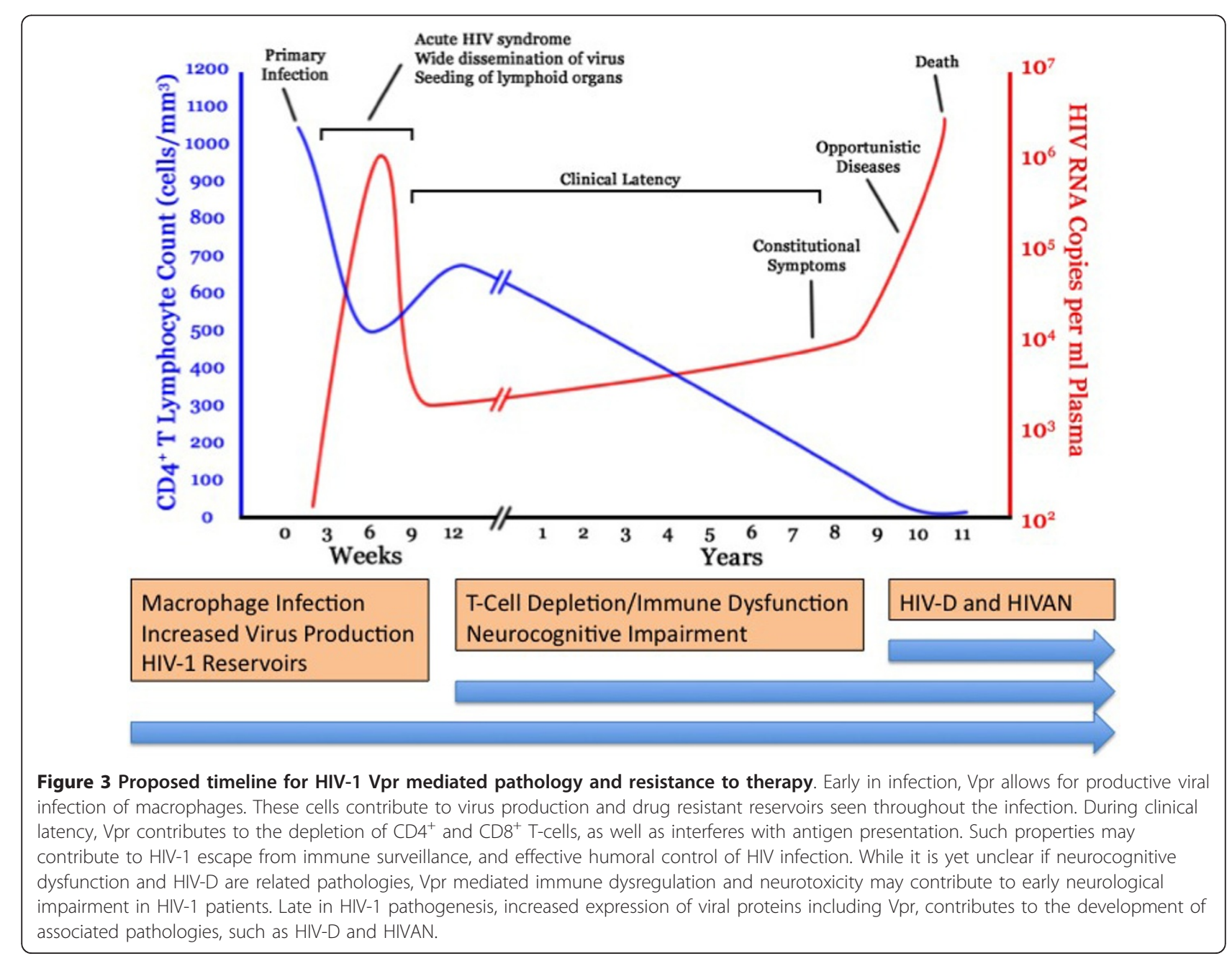


this notion. Vpr/Vpx defective SIV virus has been shown to have a greatly attenuated course with no progression to AIDS in rhesus monkeys [120]. In HIV1 , Vpx is absent and $\mathrm{Vpr}$ is thought to carry out Vpx functions, suggesting that in humans a Vpr deletion would have similar effects. Infection of $\mathrm{Vpr}$ defective HIV-1 into tonsilar histocultures showed a fifty percent reduction in HIV-1 production, even though macrophages represented a small portion of total infectable cells [214]. Further, an accidental infection of a lab worker with HIV-1 containing a frame shift mutation in codon 73 of the Vpr gene as well as infection of rhesus macaques with $\mathrm{Vpr}$ mutated virus resulted in spontaneous reversion of the $\mathrm{Vpr}$ defective virus to the WT phenotype, which implies that Vpr containing virus obtained a selective advantage over the Vpr mutant [134,215]. Vpr has also been shown to reduce the efficacy of DNA and SIV-Nef vaccination in vivo, suggesting that in the absence of $\mathrm{Vpr}$ a more effective immune response to HIV would be possible $[183,184]$. Finally, a recent study of six vertically infected children that presented as long-term nonprogressors reported that every patient had a mutated Vpr gene in addition to mutations in other genes that were not present in all patients [216]. Interestingly, all of these mutations involved a decrease in Vpr's apoptotic effects, suggesting that the cytotoxic properties of $\mathrm{Vpr}$ are of key clinical importance. However, another report suggests that these effects are more related to nuclear localization [217]. One of the major clinical consequences of $\mathrm{Vpr}$ in HIV-1 infected patients is the existence of viral reservoirs in macrophages. Nucleoside reverse transcriptase inhibitors (NRTIs) are more effective in macrophages than in $\mathrm{CD} 4^{+} \mathrm{T}$-cells for early viral inhibition; non-NRTIs are equally effective in macrophages and in $\mathrm{CD} 4^{+} \mathrm{T}$-cells for early infection (for review see [218]). Protease inhibitors, however, require a much higher dose to effectively control HIV1 infection in macrophages than in $\mathrm{CD}_{4}^{+} \mathrm{T}$-cells, and it is unknown if they achieve the concentrations needed to inhibit macrophage mediated HIV-1 production in compartments such as CNS or testes. While NRTIs, non-NRTIs and protease inhibitors prevent the cell to cell spread of HIV-1 infection, it is unknown how efficiently these drugs address virus produced from infected macrophages in vivo. There is currently no therapeutic approach for eliminating macrophage reservoirs that represent drug resistant reservoirs of HIV-1 infection and contribute to the pathogenesis of AIDS. Nanotechnology-based drug delivery systems have been proposed as one method for delivering drugs more effectively to macrophages, especially those in relatively inaccessible body compartments $[219,220]$. These novel technologies offer ways to better deliver currently available medications, but do not address the survival of persistently infected HIV-1 reservoirs.

A therapeutic approach to target HIV-1 infected mononuclear cells would be to employ specific cytokines or cellular kinase inhibitors. One candidate, TNF-related apoptosis-inducing ligand (TRAIL), has been shown to cause HIV-1 infected macrophages to undergo cell death. However, M-CSF, which is upregulated in HIV-1 infected cells, downregulates TRAIL-R1/DR4 [221]. Imatinib, a tyrosine kinase inhibitor that has some cross reactivity to colony stimulating factor-1 receptor (CSF$1 \mathrm{R})$, the receptor for M-CSF, restores the effect of TRAIL on infected MDM cells [221]. TRAIL has been shown to act through the PI3/Akt pathway [222] and consequently other PI3/Akt inhibitors have similar effects on infected MDM cells [223]. Additionally, morphine in combination with gp160 has been shown to cause apoptosis in mononuclear cells [224]. In combination with cART therapy, a clinical approach to target the anti-apoptotic pathways in HIV-1 infected macrophages may yield more effective therapies.

Another approach for targeting macrophage reservoirs is to target the specific host mediators of Vpr function. Heat shock proteins have been proposed as cellular targets of $\mathrm{Vpr}$ and a mechanism of antiviral response (for review see [225]). HSP 27 inhibits $\mathrm{Vpr}$ dependent $\mathrm{G}_{2}$ arrest and cell death in T-lymphocytes when expressed exogenously, but does not seem to inhibit viral replication in macrophages [226]. Another heat shock protein, HSP 70, can inhibit HIV-1 replication in a Vpr dependent manner as well as reduce $G_{2}$ arrest in proliferating cells [227]. HSP 70, however, can replace Vpr function in Vpr defective viruses as well as have anti-viral properties in non-proliferating macrophages [228]. As heat shock response is protective, increasing heat shock pathways could promote the survival of chronically infected cells. In light of the recent findings suggesting that $\mathrm{Vpr}$ mediated apoptotic effects are important in pathogenesis, and that $\mathrm{G}_{2}$ arrest apoptosis and NK mediated destruction of T-cells depends on $\mathrm{Vpr}$ binding to DCAF-1, targeting the Vpr ubiquitination pathways may also be useful for clinical intervention. Additionally, HAX-1 associates with Vpr, and suppresses Vpr proapoptotic effects, suggesting that molecules that bind to this site on Vpr may be used to neutralize Vpr's immunosuppressive effects [229]. Alternatively, the anti-apoptotic effects of $\mathrm{Vpr}$ in HIV-1 infected cells may contribute to the persistence of viral reservoirs in vivo. The Tat mediated upregulation of c-Flip, which prevents TRAIL toxicity, has been proposed as one mechanism of the differential effects of $\mathrm{Vpr}$ in infected and noninfected cells and may prove to be a good target for inducing apoptosis in chronically HIV-1 infected macrophages [230]. 
Several pharmacological approaches have already been suggested to target $\mathrm{Vpr}$ pathways. As many $\mathrm{Vpr}$ mediated effects depend on GR activity, RU486 has been proposed as a therapy for HIV-1 and has been shown to suppress HIV-1 replication in infected mononuclear cells and to suppress Vpr mediated downregulation of IL-12 and other cytokines [117,209]. Vpr is necessary for viral PIC entry into the nucleus of nondividing cells and therefore this property of Vpr has also been investigated as a potential avenue of therapy. CNIH0294, a specific inhibitor of HIV nuclear localization, was shown to indeed inhibit viral production. It was found to diminish infection in PBMCs and macrophages, which would not necessarily deplete viral reservoirs but may help prevent new macrophage infection [231]. More recently, a study has demonstrated that hematoxylin is a specific inhibitor of the Vpr/importin$\alpha$ interaction and consequently prevented the nuclear import of the HIV PIC complex [232]. In summary, many studies have proposed targeting the cellular effects of $\mathrm{Vpr}$ as a way of treating the consequences of $\mathrm{Vpr}$ function in HIV-1 infection. In combination with established cART regiments, these approaches may lower viral loads, increase immune response, and even contribute to the depletion of viral reservoirs thus improving the clinical outcome in HIV patients.

\section{Vpr as a pharmacotherapeutic and delivery agent}

$\mathrm{Vpr}$ is a multifunctional protein that is able to efficiently facilitate many HIV-1 functions. Some of these properties, however, lend themselves for use in the clinic. Importantly, Vpr can traffic into cells [75] and is incorporated into HIV particles [12,233]. Further, the Vpr peptide region from R14-88 has been used to introduce other protein products into HIV-1 particles [234]. As a result, $\mathrm{Vpr}$ has been explored as a vector system for drug delivery by conjugation to apolipoprotein $\mathrm{B}$ mRNA editing enzyme, catalytic peptide 3G (Vpr14-88-Apobec3G) [235]. Apobec3G has strong antiviral effects in Vif deficient viruses, but in the presence of Vif loses the ability to incorporate into virons and therefore its therapeutic efficacy [236,237]. The fusion of Vpr 14-88 to Apobec3G facilitates packaging into the HIV-1 particles and restores the ability of Apobec $3 G$ to inhibit viral replication. These studies demonstrate that the use of Vpr to amplify the effect of antiviral drugs or facilitate drug delivery is a promising avenue for HIV therapy.

The discoveries of other properties of $\mathrm{Vpr}$, including induction of $G_{2}$ cell cycle arrest and apoptosis, have led the argument that Vpr has efficacy as an anti-cancer agent [238]. Further, Vpr induction of apoptosis seems to be independent of $\mathrm{p} 53$ function, suggesting that mutations in p53 commonly seen in various tumor types will not prevent the potential therapeutic efficacy of Vpr [193]. Other studies have also provided support for the anti-cancer application of Vpr by showing that $\mathrm{Vpr}$ induces greater apoptosis in cells undergoing active replication, implying that this toxic effect would be particularly targeted to cancer cells $[73,209]$. However, Vpr, like other chemotherapeutic agents, also possesses the ability to transform cells as double stranded breaks and aneuploidy have been reported in cell lines [239]. The consequences of $\mathrm{Vpr}$ on mitogenic transformation in vivo require further assessment and remain one potential limitation of such a therapeutic approach.

\section{Conclusion}

More than two decades of research on Vpr has greatly contributed to the knowledge scientists and clinicians have available about HIV-1 pathogenesis. The findings revealed that $\mathrm{Vpr}$, while not essential for viral replication per se, is a biologically important, playing a critical role in the infection of non-dividing target cells including macrophages and resting $\mathrm{T}$-cells. Vpr promotes infection of dividing as well as non-dividing cells through a variety of effects including, nuclear localization, cell cycle arrest, apoptosis, and other effects due to DCAF-1 binding, as well as transactivation of host and viral genes. These activities of $\mathrm{Vpr}$ are likely responsible for many aspects of HIV-1 infection as well as associated pathology seen in AIDS. With the advent and success of cART therapy, HIV-1 infection has transformed from an untreatable disease to a more manageable chronic condition. Current investigations for new therapies represent an ongoing area of basic science research that holds great priority due to cART resistant reservoirs of HIV-1 infection in vivo. Vpr mediated pathogenesis is one avenue of investigation that holds promise when combined with other therapeutic approaches. Further basic and translational studies will be required to generate future therapeutic advances targeting Vpr function. Such studies could target Vpr as well as a variety of host-virus interaction pathways.

\section{Acknowledgements and Funding}

The figures created used images found in Science Slides (Visi Science Inc., Chapel Hill, NC). This work was supported by the National Institutes of Health under Ruth L. Kirschstein National Research Service Award (T32MH079785, Interdisciplinary and Translational Research Training in NeuroAIDS) providing support to Michael Kogan. Jay Rappaport is supported by R01 grants from the NINDS and NIMH. The authors would also like to thank Michael Jan, a fellow student in the MD/PhD program at Temple University, for extensive help in proofreading of this manuscript.

\section{Authors' contributions}

MK conducted a literature review and wrote the above material. MK also created the figures presented in the paper. JR organized the ideas presented in this review and helped to edit the content so that it is relevant to current HIV research. JR also suggested ideas on how to illustrate the figures and highlighted important concepts that needed to be included. Both authors read and approved the final manuscript. 


\section{Competing interests}

The authors declare that they have no competing interests.

Received: 25 October 2010 Accepted: 13 April 2011

Published: 13 April 2011

\section{References}

1. Cohen EA, Terwilliger EF, Jalinoos Y, Proulx J, Sodroski JG, Haseltine WA: Identification of HIV-1 vpr product and function. J Acquir Immune Defic Syndr 1990, 3:11-18.

2. Yuan X, Matsuda Z, Matsuda M, Essex M, Lee TH: Human immunodeficiency virus vpr gene encodes a virion-associated protein. AIDS Res Hum Retroviruses 1990, 6:1265-1271.

3. Emerman M: HIV-1, Vpr and the cell cycle. Curr Biol 1996, 6:1096-1103.

4. Planelles V, Jowett JB, Li QX, Xie Y, Hahn B, Chen IS: Vpr-induced cell cycle arrest is conserved among primate lentiviruses. J Virol 1996, 70:2516-2524.

5. Tristem M, Marshall C, Karpas A, Hill F: Evolution of the primate lentiviruses: evidence from vpx and vpr. Embo J 1992, 11:3405-3412.

6. Feldherr $\mathrm{CM}$, Feldherr $\mathrm{AB}$ : The nuclear membrane as a barrier to the free diffusion of proteins. Nature 1960, 185:250-251.

7. Lewis PF, Emerman M: Passage through mitosis is required for oncoretroviruses but not for the human immunodeficiency virus. I Virol 1994, 68:510-516.

8. Roe T, Reynolds TC, Yu G, Brown PO: Integration of murine leukemia virus DNA depends on mitosis. Embo J 1993, 12:2099-2108.

9. Lewis $\mathrm{P}$, Hensel $\mathrm{M}$, Emerman M: Human immunodeficiency virus infection of cells arrested in the cell cycle. Embo J 1992, 11:3053-3058.

10. Bukrinsky MI, Sharova N, Dempsey MP, Stanwick TL, Bukrinskaya AG, Haggerty S, Stevenson M: Active nuclear import of human immunodeficiency virus type 1 preintegration complexes. Proc Natl Acad Sci USA 1992, 89:6580-6584

11. Di Marzio P, Choe S, Ebright M, Knoblauch R, Landau NR: Mutational analysis of cell cycle arrest, nuclear localization and virion packaging of human immunodeficiency virus type 1 Vpr. J Virol 1995, 69:7909-7916.

12. Lu YL, Spearman P, Ratner L: Human immunodeficiency virus type 1 viral protein R localization in infected cells and virions. J Virol 1993, 67:6542-6550.

13. Mahalingam S, Collman RG, Patel M, Monken CE, Srinivasan A: Functional analysis of HIV-1 Vpr: identification of determinants essential for subcellular localization. Virology 1995, 212:331-339.

14. Gallay P, Hope T, Chin D, Trono D: HIV-1 infection of nondividing cells through the recognition of integrase by the importin/karyopherin pathway. Proc Natl Acad Sci USA 1997, 94:9825-9830.

15. Arhel NJ, Souquere-Besse $S$, Munier S, Souque P, Guadagnini S, Rutherford S, Prevost MC, Allen TD, Charneau P: HIV-1 DNA Flap formation promotes uncoating of the pre-integration complex at the nuclear pore. EMBO J 2007, 26:3025-3037.

16. Dismuke DJ, Aiken C: Evidence for a functional link between uncoating of the human immunodeficiency virus type 1 core and nuclear import of the viral preintegration complex. J Virol 2006, 80:3712-3720.

17. Gorlich D: Nuclear protein import. Curr Opin Cell Biol 1997, 9:412-419.

18. Herold A, Truant R, Wiegand H, Cullen BR: Determination of the functional domain organization of the importin alpha nuclear import factor. J Cell Biol 1998, 143:309-318.

19. Kobe B: Autoinhibition by an internal nuclear localization signal revealed by the crystal structure of mammalian importin alpha. Nat Struct Biol 1999, 6:388-397.

20. Moore MS, Blobel G: Purification of a Ran-interacting protein that is required for protein import into the nucleus. Proc Natl Acad Sci USA 1994, 91:10212-10216

21. Moore MS, Blobel G: The GTP-binding protein Ran/TC4 is required for protein import into the nucleus. Nature 1993, 365:661-663.

22. Paschal BM, Gerace L: Identification of NTF2, a cytosolic factor for nuclear import that interacts with nuclear pore complex protein p62. J Cell Biol 1995, 129:925-937.

23. Melchior F, Paschal B, Evans J, Gerace L: Inhibition of nuclear protein import by nonhydrolyzable analogues of GTP and identification of the small GTPase Ran/TC4 as an essential transport factor. J Cell Biol 1993, 123:1649-1659.
24. Melchior F, Guan T, Yokoyama N, Nishimoto T, Gerace L: GTP hydrolysis by Ran occurs at the nuclear pore complex in an early step of protein import. J Cell Biol 1995, 131:571-581.

25. Kotera I, Sekimoto T, Miyamoto Y, Saiwaki T, Nagoshi E, Sakagami H, Kondo $\mathrm{H}$, Yoneda Y: Importin alpha transports CaMKIV to the nucleus without utilizing importin beta. Embo J 2005, 24:942-951.

26. Takizawa CG, Weis K, Morgan DO: Ran-independent nuclear import of cyclin B1-Cdc2 by importin beta. Proc Natl Acad Sci USA 1999, 96:7938-7943.

27. Aitchison JD, Blobel G, Rout MP: Kap104p: a karyopherin involved in the nuclear transport of messenger RNA binding proteins. Science 1996, 274:624-627.

28. Fridell RA, Truant $R$, Thorne $L$, Benson RE, Cullen BR: Nuclear import of hnRNP A1 is mediated by a novel cellular cofactor related to karyopherin-beta. J Cell Sci 1997, 110(Pt 11):1325-1331.

29. Michael WM, Choi M, Dreyfuss G: A nuclear export signal in hnRNP A1: a signal-mediated, temperature-dependent nuclear protein export pathway. Cell 1995, 83:415-422.

30. Pollard WW, Michael WM, Nakielny S, Siomi MC, Wang F, Dreyfuss G: A novel receptor-mediated nuclear protein import pathway. Cell 1996, 86:985-994.

31. Siomi $H$, Dreyfuss $G$ : A nuclear localization domain in the hnRNP A1 protein. J Cell Biol 1995, 129:551-560

32. Nakielny S, Siomi MC, Siomi H, Michael WM, Pollard V, Dreyfuss G: Transportin: nuclear transport receptor of a novel nuclear protein import pathway. Exp Cell Res 1996, 229:261-266.

33. Palacios I, Weis K, Klebe C, Mattaj IW, Dingwall C: RAN/TC4 mutants identify a common requirement for snRNP and protein import into the nucleus. J Cell Biol 1996, 133:485-494.

34. Jenkins Y, McEntee M, Weis K, Greene WC: Characterization of HIV-1 vpr nuclear import: analysis of signals and pathways. J Cell Biol 1998, 143:875-885.

35. Efthymiadis A, Shao H, Hubner S, Jans DA: Kinetic characterization of the human retinoblastoma protein bipartite nuclear localization sequence (NLS) in vivo and in vitro. A comparison with the SV40 large T-antigen NLS. J Biol Chem 1997, 272:22134-22139.

36. Gorlich D, Henklein P, Laskey RA, Hartmann E: A 41 amino acid motif in importin-alpha confers binding to importin-beta and hence transit into the nucleus. Embo J 1996, 15:1810-1817.

37. Jans DA, Jans $P$, Julich T, Briggs $L$, Xiao CY, Piller SC: Intranuclear binding by the HIV-1 regulatory protein VPR is dependent on cytosolic factors. Biochem Biophys Res Commun 2000, 270:1055-1062.

38. Nitahara-Kasahara Y, Kamata M, Yamamoto T, Zhang X, Miyamoto Y, Muneta K, lijima S, Yoneda Y, Tsunetsugu-Yokota Y, Aida Y: Novel nuclear import of Vpr promoted by importin alpha is crucial for human immunodeficiency virus type 1 replication in macrophages. J Virol 2007, 81:5284-5293.

39. Kamata M, Nitahara-Kasahara Y, Miyamoto Y, Yoneda Y, Aida Y: Importinalpha promotes passage through the nuclear pore complex of human immunodeficiency virus type 1 Vpr. J Virol 2005, 79:3557-3564.

40. Balliet JW, Kolson DL, Eiger G, Kim FM, McGann KA, Srinivasan A, Collman R: Distinct effects in primary macrophages and lymphocytes of the human immunodeficiency virus type 1 accessory genes vpr, vpu, and nef: mutational analysis of a primary HIV-1 isolate. Virology 1994, 200:623-631.

41. Connor Rl, Chen BK, Choe S, Landau NR: Vpr is required for efficient replication of human immunodeficiency virus type-1 in mononuclear phagocytes. Virology 1995, 206:935-944

42. Hattori N, Michaels F, Fargnoli K, Marcon L, Gallo RC, Franchini G: The human immunodeficiency virus type 2 vpr gene is essential for productive infection of human macrophages. Proc Natl Acad Sci USA 1990, 87:8080-8084.

43. Ogawa K, Shibata R, Kiyomasu T, Higuchi I, Kishida Y, Ishimoto A, Adachi A: Mutational analysis of the human immunodeficiency virus vpr open reading frame. J Virol 1989, 63:4110-4114.

44. Blomer U, Naldini L, Kafri T, Trono D, Verma IM, Gage FH: Highly efficient and sustained gene transfer in adult neurons with a lentivirus vector. $J$ Virol 1997, 71:6641-6649.

45. Agostini I, Popov S, Hao T, Li JH, Dubrovsky L, Chaika O, Chaika N, Lewis R, Bukrinsky M: Phosphorylation of Vpr regulates HIV type 1 nuclear import and macrophage infection. AIDS Res Hum Retroviruses 2002, 18:283-288. 
46. Caly L, Saksena NK, Piller SC, Jans DA: Impaired nuclear import and viral incorporation of Vpr derived from a HIV long-term non-progressor. Retrovirology 2008, 5:67.

47. Fouchier RA, Meyer BE, Simon JH, Fischer U, Albright AV, GonzalezScarano F, Malim MH: Interaction of the human immunodeficiency virus type 1 Vpr protein with the nuclear pore complex. J Virol 1998, 72:6004-6013

48. Gallay P, Stitt V, Mundy C, Oettinger M, Trono D: Role of the karyopherin pathway in human immunodeficiency virus type 1 nuclear import. J Virol 1996, 70:1027-1032.

49. Jacquot G, Le Rouzic E, David A, Mazzolini J, Bouchet J, Bouaziz S, Niedergang F, Pancino G, Benichou S: Localization of HIV-1 Vpr to the nuclear envelope: impact on Vpr functions and virus replication in macrophages. Retrovirology 2007, 4:84.

50. Vodicka MA, Koepp DM, Silver PA, Emerman M: HIV-1 Vpr interacts with the nuclear transport pathway to promote macrophage infection. Genes Dev 1998, 12:175-185.

51. Popov S, Rexach M, Ratner L, Blobel G, Bukrinsky M: Viral protein R regulates docking of the HIV-1 preintegration complex to the nuclear pore complex. J Biol Chem 1998, 273:13347-13352.

52. Keele BF, Giorgi EE, Salazar-Gonzalez JF, Decker JM, Pham KT, Salazar MG, Sun C, Grayson T, Wang S, Li H, et al: Identification and characterization of transmitted and early founder virus envelopes in primary HIV-1 infection. Proc Natl Acad Sci USA 2008, 105:7552-7557.

53. Fischer W, Ganusov W, Giorgi EE, Hraber PT, Keele BF, Leitner T, Han CS, Gleasner CD, Green L, Lo CC, et al: Transmission of single HIV-1 genomes and dynamics of early immune escape revealed by ultra-deep sequencing. PLoS One 2010, 5:e12303.

54. lijima S, Nitahara-Kasahara Y, Kimata K, Zhong Zhuang W, Kamata M, Isogai M, Miwa M, Tsunetsugu-Yokota Y, Aida Y: Nuclear localization of Vpr is crucial for the efficient replication of HIV-1 in primary CD4+ T cells. Virology 2004, 327:249-261.

55. Bukrinsky MI, Haffar OK: HIV-1 nuclear import: in search of a leader. Front Biosci 1997, 2:d578-587.

56. Yamashita M, Perez O, Hope TJ, Emerman M: Evidence for direct involvement of the capsid protein in HIV infection of nondividing cells. PLoS Pathog 2007, 3:1502-1510.

57. Craigo JK, Montelaro RC: Lentivirus Tropism and Disease. In Lentiviruses and Macrophages: Molecular and Cellular Interactions. Edited by: Desport M. Norfolk: Caister Academic Press; 2010:1-24

58. Morellet N, Bouaziz S, Petitjean P, Roques BP: NMR structure of the HIV-1 regulatory protein VPR. J Mol Biol 2003, 327:215-227

59. Mahalingam S, Ayyavoo V, Patel M, Kieber-Emmons T, Weiner DB: Nuclear import, virion incorporation, and cell cycle arrest/differentiation are mediated by distinct functional domains of human immunodeficiency virus type 1 Vpr. J Virol 1997, 71:6339-6347.

60. Nie Z, Bergeron D, Subbramanian RA, Yao XJ, Checroune F, Rougeau N, Cohen EA: The putative alpha helix 2 of human immunodeficiency virus type $1 \mathrm{Vpr}$ contains a determinant which is responsible for the nuclear translocation of proviral DNA in growth-arrested cells. J Virol 1998, 72:4104-4115.

61. Singh SP, Tomkowicz B, Lai D, Cartas M, Mahalingam S, Kalyanaraman VS, Murali R, Srinivasan A: Functional role of residues corresponding to helical domain II (amino acids 35 to 46) of human immunodeficiency virus type 1 Vpr. J Virol 2000, 74:10650-10657.

62. Yao XJ, Subbramanian RA, Rougeau N, Boisvert F, Bergeron D, Cohen EA: Mutagenic analysis of human immunodeficiency virus type $1 \mathrm{Vpr}$ : role of a predicted $\mathrm{N}$-terminal alpha-helical structure in Vpr nuclear localization and virion incorporation. J Virol 1995, 69:7032-7044.

63. Fritz JV, Didier P, Clamme JP, Schaub E, Muriaux D, Cabanne C, Morellet N, Bouaziz S, Darlix JL, Mely Y, de Rocquigny H: Direct Vpr-Vpr interaction in cells monitored by two photon fluorescence correlation spectroscopy and fluorescence lifetime imaging. Retrovirology 2008, 5:87.

64. Agostini I, Popov S, Li J, Dubrovsky L, Hao T, Bukrinsky M: Heat-shock protein 70 can replace viral protein R of HIV-1 during nuclear import of the viral preintegration complex. Exp Cell Res 2000, 259:398-403.

65. Popov S, Rexach M, Zybarth G, Reiling N, Lee MA, Ratner L, Lane CM, Moore MS, Blobel G, Bukrinsky M: Viral protein R regulates nuclear import of the HIV-1 pre-integration complex. Embo J 1998, 17:909-917.
66. Kamata M, Aida Y: Two putative alpha-helical domains of human immunodeficiency virus type $1 \mathrm{Vpr}$ mediate nuclear localization by at least two mechanisms. J Virol 2000, 74:7179-7186.

67. Le Rouzic E, Mousnier A, Rustum C, Stutz F, Hallberg E, Dargemont C, Benichou S: Docking of HIV-1 Vpr to the nuclear envelope is mediated by the interaction with the nucleoporin hCG1. J Biol Chem 2002, 277:45091-45098.

68. Radu A, Moore MS, Blobel G: The peptide repeat domain of nucleoporin Nup98 functions as a docking site in transport across the nuclear pore complex. Cell 1995, 81:215-222.

69. Rexach M, Blobel G: Protein import into nuclei: association and dissociation reactions involving transport substrate, transport factors, and nucleoporins. Cell 1995, 83:683-692.

70. Kutay U, Izaurralde E, Bischoff FR, Mattaj IW, Gorlich D: Dominant-negative mutants of importin-beta block multiple pathways of import and export through the nuclear pore complex. Embo J 1997, 16:1153-1163.

71. Karni O, Friedler A, Zakai N, Gilon C, Loyter A: A peptide derived from the $\mathrm{N}$-terminal region of HIV-1 Vpr promotes nuclear import in permeabilized cells: elucidation of the NLS region of the Vpr. FEBS Lett 1998, 429:421-425.

72. Zhou Y, Lu Y, Ratner L: Arginine residues in the C-terminus of HIV-1 Vpr are important for nuclear localization and cell cycle arrest. Virology 1998, 242:414-424.

73. Stewart SA, Poon B, Jowett JB, Chen IS: Human immunodeficiency virus type 1 Vpr induces apoptosis following cell cycle arrest. J Virol 1997, 71:5579-5592.

74. Levy DN, Refaeli Y, MacGregor RR, Weiner DB: Serum Vpr regulates productive infection and latency of human immunodeficiency virus type 1. Proc Natl Acad Sci USA 1994, 91:10873-10877.

75. Levy DN, Refaeli Y, Weiner DB: Extracellular Vpr protein increases cellular permissiveness to human immunodeficiency virus replication and reactivates virus from latency. J Virol 1995, 69:1243-1252.

76. Agostini I, Navarro JM, Rey F, Bouhamdan M, Spire B, Vigne R, Sire J: The human immunodeficiency virus type $1 \mathrm{Vpr}$ transactivator: cooperation with promoter-bound activator domains and binding to TFIIB. J Mol Biol 1996, 261:599-606

77. Cohen EA, Dehni G, Sodroski JG, Haseltine WA: Human immunodeficiency virus vpr product is a virion-associated regulatory protein. J Virol 1990, 64:3097-3099

78. Wang L, Mukherjee S, Jia F, Narayan O, Zhao LJ: Interaction of virion protein Vpr of human immunodeficiency virus type 1 with cellular transcription factor Sp1 and trans-activation of viral long terminal repeat. J Biol Chem 1995, 270:25564-25569.

79. Ghosh D: Glucocorticoid receptor-binding site in the human immunodeficiency virus long terminal repeat. J Virol 1992, 66:586-590.

80. Katsanakis CD, Sekeris CE, Spandidos DA: The human immunodeficiency virus long terminal repeat contains sequences showing partial homology to glucocorticoid responsive elements. Anticancer Res 1991, 11:381-383.

81. McAllister JJ, Phillips D, Millhouse S, Conner J, Hogan T, Ross HL, Wigdahl B: Analysis of the HIV-1 LTR NF-kappaB-proximal Sp site III: evidence for cell type-specific gene regulation and viral replication. Virology 2000, 274:262-277.

82. Soudeyns H, Geleziunas R, Shyamala G, Hiscott J, Wainberg MA: Identification of a novel glucocorticoid response element within the genome of the human immunodeficiency virus type 1. Virology 1993, 194:758-768

83. Verhoef K, Sanders RW, Fontaine V, Kitajima S, Berkhout B: Evolution of the human immunodeficiency virus type 1 long terminal repeat promoter by conversion of an NF-kappaB enhancer element into a GABP binding site. J Virol 1999, 73:1331-1340.

84. Vanitharani R, Mahalingam S, Rafaeli Y, Singh SP, Srinivasan A, Weiner DB, Ayyavoo V: HIV-1 Vpr transactivates LTR-directed expression through sequences present within -278 to -176 and increases virus replication in vitro. Virology 2001, 289:334-342.

85. Felzien LK, Woffendin C, Hottiger MO, Subbramanian RA, Cohen EA, Nabel GJ: HIV transcriptional activation by the accessory protein, VPR, is mediated by the p300 co-activator. Proc Natl Acad Sci USA 1998, 95:5281-5286. 
86. Kino T, Tsukamoto M, Chrousos G: Transcription factor TFIIH components enhance the GR coactivator activity but not the cell cycle-arresting activity of the human immunodeficiency virus type-1 protein Vpr. Biochem Biophys Res Commun 2002, 298:17-23.

87. Sawaya BE, Khalili K, Rappaport J, Serio D, Chen W, Srinivasan A, Amini S Suppression of HIV-1 transcription and replication by a Vpr mutant. Gene Ther 1999, 6:947-950.

88. Sawaya BE, Khalili K, Gordon J, Taube R, Amini S: Cooperative interaction between HIV-1 regulatory proteins Tat and Vpr modulates transcription of the viral genome. J Biol Chem 2000, 275:35209-35214.

89. Refaeli $Y$, Levy DN, Weiner DB: The glucocorticoid receptor type II complex is a target of the HIV-1 vpr gene product. Proc Natl Acad Sci USA 1995, 92:3621-3625.

90. Kino T, Gragerov A, Kopp JB, Stauber RH, Pavlakis GN, Chrousos GP: The HIV-1 virion-associated protein vpr is a coactivator of the human glucocorticoid receptor. J Exp Med 1999, 189:51-62.

91. Sherman MP, de Noronha CM, Pearce D, Greene WC: Human immunodeficiency virus type $1 \mathrm{Vpr}$ contains two leucine-rich helices that mediate glucocorticoid receptor coactivation independently of its effects on G(2) cell cycle arrest. J Virol 2000, 74:8159-8165.

92. Kino T, Gragerov A, Slobodskaya O, Tsopanomichalou M, Chrousos GP Pavlakis GN: Human immunodeficiency virus type 1 (HIV-1) accessory protein Vpr induces transcription of the HIV-1 and glucocorticoidresponsive promoters by binding directly to p300/CBP coactivators. $J$ Virol 2002, 76:9724-9734.

93. Thotala D, Schafer EA, Tungaturthi PK, Majumder B, Janket ML, Wagner M, Srinivasan A, Watkins S, Ayyavoo V: Structure-functional analysis of human immunodeficiency virus type 1 (HIV-1) Vpr: role of leucine residues on Vpr-mediated transactivation and virus replication. Virology 2004, 328:89-100.

94. Ramanathan MP, Curley E, Su M, Chambers JA, Weiner DB: Carboxyl terminus of hVIP/mov34 is critical for HIV-1-Vpr interaction and glucocorticoid-mediated signaling. J Biol Chem 2002, 277:47854-47860

95. Muthumani $\mathrm{K}$, Choo AY, Zong WX, Madesh M, Hwang DS, Premkumar A, Thieu KP, Emmanuel J, Kumar S, Thompson CB, Weiner DB: The HIV-1 Vpr and glucocorticoid receptor complex is a gain-of-function interaction that prevents the nuclear localization of PARP-1. Nat Cell Biol 2006, 8:170-179.

96. Poli G, Kinter A, Justement JS, Kehrl JH, Bressler P, Stanley S, Fauci AS: Tumor necrosis factor alpha functions in an autocrine manner in the induction of human immunodeficiency virus expression. Proc Natl Acad Sci USA 1990, 87:782-785.

97. Lenardo MJ, Baltimore D: NF-kappa B: a pleiotropic mediator of inducible and tissue-specific gene control. Cell 1989, 58:227-229.

98. Chang HK, Gallo RC, Ensoli B: Regulation of Cellular Gene Expression and Function by the Human Immunodeficiency Virus Type 1 Tat Protein. J Biomed Sci 1995, 2:189-202.

99. Chatterton RT Jr, Green D, Harris S, Grossman A, Hechter O: Longitudinal study of adrenal steroids in a cohort of HIV-infected patients with hemophilia. J Lab Clin Med 1996, 127:545-552.

100. Kawa SK, Thompson EB: Lymphoid cell resistance to glucocorticoids in HIV infection. J Steroid Biochem Mol Biol 1996, 57:259-263.

101. Lortholary O, Christeff N, Casassus P, Thobie N, Veyssier P, Trogoff B, Torri O, Brauner M, Nunez EA, Guillevin L: Hypothalamo-pituitary-adrenal function in human immunodeficiency virus-infected men. J Clin Endocrinol Metab 1996, 81:791-796.

102. Laudat A, Blum L, Guechot J, Picard O, Cabane J, Imbert JC, Giboudeau J: Changes in systemic gonadal and adrenal steroids in asymptomatic human immunodeficiency virus-infected men: relationship with the CD4 cell counts. Eur J Endocrinol 1995, 133:418-424.

103. Biglino A, Limone P, Forno B, Pollono A, Cariti G, Molinatti GM, Gioannini P: Altered adrenocorticotropin and cortisol response to corticotropinreleasing hormone in HIV-1 infection. Eur J Endocrinol 1995, 133:173-179.

104. Kumar M, Kumar AM, Morgan R, Szapocznik J, Eisdorfer C: Abnormal pituitary-adrenocortical response in early HIV-1 infection. J Acquir Immune Defic Syndr 1993, 6:61-65.

105. Kino T, Kopp JB, Chrousos GP: Glucocorticoids suppress human immunodeficiency virus type-1 long terminal repeat activity in a cell type-specific, glucocorticoid receptor-mediated fashion: direct protective effects at variance with clinical phenomenology. J Steroid Biochem Mol Biol 2000, 75:283-290.
106. Laurence J, Sellers MB, Sikder SK: Effect of glucocorticoids on chronic human immunodeficiency virus (HIV) infection and HIV promotermediated transcription. Blood 1989, 74:291-297.

107. Mitra D, Sikder S, Laurence J: Inhibition of tat-activated, HIV-1 long terminal repeat-mediated gene expression by glucocorticoids. AIDS Res Hum Retroviruses 1993, 9:1055-1056.

108. Mitra D, Sikder SK, Laurence J: Role of glucocorticoid receptor binding sites in the human immunodeficiency virus type 1 long terminal repeat in steroid-mediated suppression of HIV gene expression. Virology 1995, 214:512-521

109. Russo FO, Patel PC, Ventura AM, Pereira CA: HIV-1 long terminal repeat modulation by glucocorticoids in monocytic and lymphocytic cell lines. Virus Res 1999, 64:87-94.

110. Furth PA, Westphal $H$, Hennighausen L: Expression from the HIV-LTR is stimulated by glucocorticoids and pregnancy. AIDS Res Hum Retroviruses 1990, 6:553-560.

111. Kinter AL, Biswas P, Alfano M, Justement JS, Mantelli B, Rizzi C, Gatti AR, Vicenzi E, Bressler P, Poli G: Interleukin-6 and glucocorticoids synergistically induce human immunodeficiency virus type- 1 expression in chronically infected U1 cells by a long terminal repeat independent post-transcriptional mechanism. Mol Med 2001, 7:668-678.

112. Hoshino S, Konishi M, Mori M, Shimura M, Nishitani C, Kuroki Y, Koyanagi $Y$, Kano S, Itabe H, Ishizaka Y: HIV-1 Vpr induces TLR4/MyD88-mediated IL-6 production and reactivates viral production from latency. J Leukoc Biol 2010, 87:1133-1143.

113. Bressler P, Poli G, Justement JS, Biswas P, Fauci AS: Glucocorticoids synergize with tumor necrosis factor alpha in the induction of HIV expression from a chronically infected promonocytic cell line. AIDS Res Hum Retroviruses 1993, 9:547-551.

114. Capitanio JP, Mendoza SP, Lerche NW, Mason WA: Social stress results in altered glucocorticoid regulation and shorter survival in simian acquired immune deficiency syndrome. Proc Natl Acad Sci USA 1998, 95:4714-4719.

115. Corley PA: Induction of interleukin-1 and glucocorticoid hormones by HIV promotes viral replication and links human chromosome 2 to AIDS pathogenesis: genetic mechanisms and therapeutic implications. Med Hypotheses 1997, 48:415-421.

116. Nair MP, Saravolatz LD, Schwartz SA: Selective inhibitory effects of stress hormones on natural killer (NK) cell activity of lymphocytes from AIDS patients. Immunol Invest 1995, 24:689-699.

117. Schafer EA, Venkatachari NJ, Ayyavoo V: Antiviral effects of mifepristone on human immunodeficiency virus type-1 (HIV-1): targeting Vpr and its cellular partner, the glucocorticoid receptor (GR). Antiviral Res 2006, 72:224-232.

118. Wiegers K, Schwarck D, Reimer R, Bohn W: Activation of the glucocorticoid receptor releases unstimulated PBMCs from an early block in HIV-1 replication. Virology 2008, 375:73-84.

119. Fletcher TM, Brichacek B, Sharova N, Newman MA, Stivahtis G, Sharp PM, Emerman M, Hahn BH, Stevenson M: Nuclear import and cell cycle arrest functions of the HIV-1 Vpr protein are encoded by two separate genes in HIV-2/SIV(SM). Embo J 1996, 15:6155-6165.

120. Gibbs JS, Lackner AA, Lang SM, Simon MA, Sehgal PK, Daniel MD, Desrosiers RC: Progression to AIDS in the absence of a gene for vpr or vpx. J Virol 1995, 69:2378-2383.

121. Subbramanian RA, Kessous-Elbaz A, Lodge R, Forget J, Yao XJ, Bergeron D, Cohen EA: Human immunodeficiency virus type $1 \mathrm{Vpr}$ is a positive regulator of viral transcription and infectivity in primary human macrophages. J Exp Med 1998, 187:1103-1111.

122. Belzile JP, Duisit G, Rougeau N, Mercier J, Finzi A, Cohen EA: HIV-1 Vprmediated G2 arrest involves the DDB1-CUL4AVPRBP E3 ubiquitin ligase. PLoS Pathog 2007, 3:e85.

123. DeHart JL, Zimmerman ES, Ardon O, Monteiro-Filho CM, Arganaraz ER, Planelles V: HIV-1 Vpr activates the G2 checkpoint through manipulation of the ubiquitin proteasome system. Virol J 2007, 4:57.

124. Hrecka K, Gierszewska M, Srivastava S, Kozaczkiewicz L, Swanson SK, Florens L, Washburn MP, Skowronski J: Lentiviral Vpr usurps Cul4-DDB1 [VprBP] E3 ubiquitin ligase to modulate cell cycle. Proc Natl Acad Sci USA 2007, 104:11778-11783.

125. Le Rouzic E, Belaïdouni N, Estrabaud E, Morel M, Rain J, Transy C, MargottinGoguet F: HIV1 Vpr arrests the cell cycle by recruiting DCAF1/NprBP, a receptor of the Cul4-DDB1 ubiquitin ligase. Cell Cycle 2007, 6:182-188. 
126. Schrofelbauer B, Hakata Y, Landau NR: HIV-1 Vpr function is mediated by interaction with the damage-specific DNA-binding protein DDB1. Proc Natl Acad Sci USA 2007, 104:4130-4135.

127. Tan L, Ehrlich E, Yu XF: DDB1 and Cul4A are required for human immunodeficiency virus type 1 Vpr-induced G2 arrest. J Virol 2007, 81:10822-10830

128. Wen X, Duus KM, Friedrich TD, de Noronha CM: The HIV1 protein Vpr acts to promote $\mathrm{G} 2$ cell cycle arrest by engaging a DDB1 and Cullin4Acontaining ubiquitin ligase complex using VprBP/DCAF1 as an adaptor. J Biol Chem 2007, 282:27046-27057.

129. Zhao L, Mukherjee S, Narayan O: Biochemical mechanism of HIV-I Vpr function. Specific interaction with a cellular protein. J Biol Chem 1994 269:15577-15582.

130. Ayinde D, Maudet C, Transy C, Margottin-Goguet F: Limelight on two HIV/ SIV accessory proteins in macrophage infection: is Vpx overshadowing Vpr? Retrovirology 2010, 7:35.

131. Casey L, Wen X, de Noronha CM: The functions of the HIV1 protein Vpr and its action through the DCAF1.DDB1.Cullin4 ubiquitin ligase. Cytokine 2010, 51:1-9.

132. Zimmerman E, Sherman M, Blackett J, Neidleman J, Kreis C, Mundt P, Williams S, Warmerdam M, Kahn J, Hecht F, et al: Human immunodeficiency virus type $1 \mathrm{Vpr}$ induces DNA replication stress in vitro and in vivo. J Virol 2006, 80:10407-10418

133. Forget J, Yao XJ, Mercier J, Cohen EA: Human immunodeficiency virus type $1 \mathrm{vpr}$ protein transactivation function: mechanism and identification of domains involved. J Mol Biol 1998, 284:915-923.

134. Goh WC, Rogel ME, Kinsey CM, Michael SF, Fultz PN, Nowak MA, Hahn BH, Emerman M: HIV-1 Vpr increases viral expression by manipulation of the cell cycle: a mechanism for selection of Vpr in vivo. Nat Med 1998, 4:65-71.

135. Igarashi T, Brown CR, Endo Y, Buckler-White A, Plishka R, Bischofberger N, Hirsch V, Martin MA: Macrophage are the principal reservoir and sustain high virus loads in rhesus macaques after the depletion of CD4+ T cells by a highly pathogenic simian immunodeficiency virus/HIV type 1 chimera (SHIV): Implications for HIV-1 infections of humans. Proc Natl Acad Sci USA 2001, 98:658-663.

136. Tristem M, Marshall C, Karpas A, Petrik J, Hill F: Origin of vpx in lentiviruses. Nature 1990, 347:341-342

137. Sharova N, Wu Y, Zhu X, Stranska R, Kaushik R, Sharkey M, Stevenson M: Primate lentiviral Vpx commandeers DDB1 to counteract a macrophage restriction. PLoS Pathog 2008, 4:e1000057.

138. Srivastava S, Swanson SK, Manel N, Florens L, Washburn MP, Skowronski J: Lentiviral Vpx accessory factor targets VprBP/DCAF1 substrate adaptor for cullin 4 E3 ubiquitin ligase to enable macrophage infection. PLOS Pathog 2008, 4:e1000059.

139. Bergamaschi A, Ayinde D, David A, Le Rouzic E, Morel M, Collin G, Descamps D, Damond F, Brun-Vezinet F, Nisole $S$, et al: The human immunodeficiency virus type $2 \mathrm{Vpx}$ protein usurps the CUL4A-DDB1 DCAF1 ubiquitin ligase to overcome a postentry block in macrophage infection. J Virol 2009, 83:4854-4860.

140. Zufferey R, Nagy D, Mandel RJ, Naldini L, Trono D: Multiply attenuated lentiviral vector achieves efficient gene delivery in vivo. Nat Biotechnol 1997, 15:871-875.

141. Cosenza MA, Zhao ML, Lee SC: HIV-1 expression protects macrophages and microglia from apoptotic death. Neuropathol Appl Neurobiol 2004, 30:478-490.

142. Fernandez Larrosa PN, Croci DO, Riva DA, Bibini M, Luzzi R, Saracco M, Mersich SE, Rabinovich GA, Peralta LM: Apoptosis resistance in HIV-1 persistently-infected cells is independent of active viral replication and involves modulation of the apoptotic mitochondrial pathway. Retrovirology 2008, 5:19.

143. Fukumori T, Akari H, Yoshida A, Fujita M, Koyama AH, Kagawa S, Adachi A Regulation of cell cycle and apoptosis by human immunodeficiency virus type 1 Vpr. Microbes Infect 2000, 2:1011-1017.

144. Yao XJ, Mouland AJ, Subbramanian RA, Forget J, Rougeau N, Bergeron D, Cohen EA: Vpr stimulates viral expression and induces cell killing in human immunodeficiency virus type 1-infected dividing Jurkat T cells. J Virol 1998, 72:4686-4693.

145. Conti L, Rainaldi G, Matarrese P, Varano B, Rivabene R, Columba S, Sato A, Belardelli F, Malorni W, Gessani S: The HIV-1 vpr protein acts as a negative regulator of apoptosis in a human lymphoblastoid T cell line: possible implications for the pathogenesis of AIDS. J Exp Med 1998, 187:403-413.

146. Rostad SW, Sumi SM, Shaw CM, Olson K, McDougall JK: Human immunodeficiency virus (HIV) infection in brains with AIDS-related leukoencephalopathy. AIDS Res Hum Retroviruses 1987, 3:363-373.

147. McArthur JC: HIV dementia: an evolving disease. J Neuroimmunol 2004, 157:3-10.

148. Kure K, Llena JF, Lyman WD, Soeiro R, Weidenheim KM, Hirano A, Dickson DW: Human immunodeficiency virus-1 infection of the nervous system: an autopsy study of 268 adult, pediatric, and fetal brains. Hum Pathol 1991, 22:700-710.

149. Porwit A, Parravicini C, Petren AL, Barkhem T, Costanzi G, Josephs S, Biberfeld P: Cell association of HIV in AIDS-related encephalopathy and dementia. Apmis 1989, 97:79-90.

150. Pumarola-Sune T, Navia BA, Cordon-Cardo C, Cho ES, Price RW: HIV antigen in the brains of patients with the AIDS dementia complex. Ann Neurol 1987, 21:490-496

151. Williams KC, Corey S, Westmoreland SV, Pauley D, Knight H, deBakker $C$ Alvarez $X$, Lackner AA: Perivascular macrophages are the primary cell type productively infected by simian immunodeficiency virus in the brains of macaques: implications for the neuropathogenesis of AIDS. J Exp Med 2001, 193:905-915.

152. Glass JD, Fedor H, Wesselingh SL, McArthur JC: Immunocytochemical quantitation of human immunodeficiency virus in the brain: correlations with dementia. Ann Neurol 1995, 38:755-762.

153. Fischer-Smith T, Tedaldi EM, Rappaport J: CD163/CD16 coexpression by circulating monocytes/macrophages in HIV: potential biomarkers for HIV infection and AIDS progression. AIDS Res Hum Retroviruses 2008, 24:417-421.

154. Pulliam L, Gascon R, Stubblebine M, McGuire D, McGrath MS: Unique monocyte subset in patients with AIDS dementia. Lancet 1997, 349:692-695.

155. Fischer-Smith T, Croul S, Sverstiuk AE, Capini C, L'Heureux D, Regulier EG, Richardson MW, Amini S, Morgello S, Khalili K, Rappaport J: CNS invasion by CD14+/CD16+ peripheral blood-derived monocytes in HIV dementia: perivascular accumulation and reservoir of HIV infection. J Neurovirol 2001, 7:528-541.

156. Achim CL, Heyes MP, Wiley CA: Quantitation of human immunodeficiency virus, immune activation factors, and quinolinic acid in AIDS brains. Clin Invest 1993, 91:2769-2775.

157. Fischer-Smith T, Croul S, Adeniyi A, Rybicka K, Morgello S, Khalili K, Rappaport J: Macrophage/microglial accumulation and proliferating cell nuclear antigen expression in the central nervous system in human immunodeficiency virus encephalopathy. Am J Pathol 2004, 164:2089-2099.

158. Fischer-Smith T, Rappaport J: Evolving paradigms in the pathogenesis of HIV-1-associated dementia. Expert Rev Mol Med 2005, 7:1-26.

159. Wheeler ED, Achim CL, Ayyavoo V: Immunodetection of human immunodeficiency virus type 1 (HIV-1) Vpr in brain tissue of HIV-1 encephalitic patients. J Neurovirol 2006, 12:200-210.

160. Piller SC, Jans P, Gage PW, Jans DA: Extracellular HIV-1 virus protein $R$ causes a large inward current and cell death in cultured hippocampal neurons: implications for AIDS pathology. Proc Natl Acad Sci USA 1998, 95:4595-4600.

161. Jones GJ, Barsby NL, Cohen EA, Holden J, Harris K, Dickie P, Jhamandas J, Power C: HIV-1 Vpr causes neuronal apoptosis and in vivo neurodegeneration. J Neurosci 2007, 27:3703-3711.

162. Sabbah EN, Roques BP: Critical implication of the (70-96) domain of human immunodeficiency virus type $1 \mathrm{Vpr}$ protein in apoptosis of primary rat cortical and striatal neurons. J Neurovirol 2005, 11:489-502.

163. Patel CA, Mukhtar M, Pomerantz RJ: Human immunodeficiency virus type $1 \mathrm{Vpr}$ induces apoptosis in human neuronal cells. J Virol 2000 74:9717-9726

164. Brenneman DE, Westbrook GL, Fitzgerald SP, Ennist DL, Elkins KL, Ruff MR, Pert CB: Neuronal cell killing by the envelope protein of HIV and its prevention by vasoactive intestinal peptide. Nature 1988, 335:639-642.

165. Venkatesh LK, Arens MQ, Subramanian T, Chinnadurai G: Selective induction of toxicity to human cells expressing human immunodeficiency virus type 1 Tat by a conditionally cytotoxic adenovirus vector. Proc Natl Acad Sci USA 1990, 87:8746-8750. 
166. Patel CA, Mukhtar M, Harley S, Kulkosky J, Pomerantz RJ: Lentiviral expression of HIV-1 Vpr induces apoptosis in human neurons. Neurovirol 2002, 8:86-99.

167. Acheampong E, Mukhtar M, Parveen Z, Ngoubilly N, Ahmad N, Patel C, Pomerantz RJ: Ethanol strongly potentiates apoptosis induced by HIV-1 proteins in primary human brain microvascular endothelial cells. Virology 2002, 304:222-234.

168. Rom I, Deshmane SL, Mukerjee R, Khalili K, Amini S, Sawaya BE: HIV-1 Vpr deregulates calcium secretion in neural cells. Brain Res 2009.

169. D'Antoni S, Berretta A, Bonaccorso CM, Bruno V, Aronica E, Nicoletti F, Catania MV: Metabotropic glutamate receptors in glial cells. Neurochem Res 2008, 33:2436-2443.

170. Kitayama H, Miura Y, Ando Y, Hoshino S, Ishizaka Y, Koyanagi Y: Human immunodeficiency virus type $1 \mathrm{Vpr}$ inhibits axonal outgrowth through induction of mitochondrial dysfunction. J Virol 2008, 82:2528-2542.

171. Hogan TH, Nonnemacher MR, Krebs FC, Henderson A, Wigdahl B: HIV-1 Vpr binding to HIV-1 LTR C/EBP cis-acting elements and adjacent regions is sequence-specific. Biomed Pharmacother 2003, 57:41-48.

172. Burdo TH, Nonnemacher M, Irish BP, Choi CH, Krebs FC, Gartner S, Wigdahl B: High-affinity interaction between HIV-1 Vpr and specific sequences that span the C/EBP and adjacent NF-kappaB sites within the HIV-1 LTR correlate with HIV-1-associated dementia. DNA Cell Biol 2004, 23:261-269.

173. Kilareski EM, Shah S, Nonnemacher MR, Wigdahl B: Regulation of HIV-1 transcription in cells of the monocyte-macrophage lineage. Retrovirology 2009, 6:118

174. Si Q, Kim MO, Zhao ML, Landau NR, Goldstein H, Lee S: Vpr- and Nefdependent induction of RANTES/CCL5 in microglial cells. Virology 2002, 301:342-353.

175. Wyatt CM, Rosenstiel PE, Klotman PE: HIV-associated nephropathy. Contrib Nephrol 2008, 159:151-161

176. Kopp J, Smith M, Nelson G, Johnson R, Freedman B, Bowden D, Oleksyk T, McKenzie L, Kajiyama H, Ahuja T, et al: MYH9 is a major-effect risk gene for focal segmental glomerulosclerosis. Nat Genet 2008, 40:1175-1184.

177. Tang P, Jerebtsova M, Przygodzki R, Ray PE: Fibroblast growth factor-2 increases the renal recruitment and attachment of HIV-infected mononuclear cells to renal tubular epithelial cells. Pediatr Nephrol 2005, 20:1708-1716.

178. Dickie P, Roberts A, Uwiera R, Witmer J, Sharma K, Kopp JB: Focal glomerulosclerosis in proviral and c-fms transgenic mice links $\mathrm{Vpr}$ expression to HIV-associated nephropathy. Virology 2004, 322:69-81.

179. Zhong J, Zuo Y, Ma J, Fogo AB, Jolicoeur P, Ichikawa I, Matsusaka T: Expression of HIV-1 genes in podocytes alone can lead to the full spectrum of HIV-1-associated nephropathy. Kidney Int 2005, 68:1048-1060.

180. Zuo Y, Matsusaka T, Zhong J, Ma J, Ma LJ, Hanna Z, Jolicoeur P, Fogo AB, Ichikawa I: HIV-1 genes vpr and nef synergistically damage podocytes, leading to glomerulosclerosis. J Am Soc Nephrol 2006, 17:2832-2843.

181. Rosenstiel PE, Gruosso T, Letourneau AM, Chan JJ, LeBlanc A, Husain M, Najfeld V, Planelles V, D'Agati VD, Klotman ME, Klotman PE: HIV-1 Vpr inhibits cytokinesis in human proximal tubule cells. Kidney Int 2008, 74:1049-1058.

182. Hiramatsu N, Hiromura K, Shigehara T, Kuroiwa T, Ideura H, Sakurai N, Takeuchi S, Tomioka M, Ikeuchi H, Kaneko Y, et al: Angiotensin II type 1 receptor blockade inhibits the development and progression of HIVassociated nephropathy in a mouse model. J Am Soc Nephrol 2007, 18:515-527.

183. Ayyavoo V, Muthumani K, Kudchodkar S, Zhang D, Ramanathan P, Dayes NS, Kim JJ, Sin Jl, Montaner LJ, Weiner DB: HIV-1 viral protein R compromises cellular immune function in vivo. Int Immunol 2002, 14:13-22.

184. Muthumani K, Bagarazzi M, Conway D, Hwang DS, Ayyavoo V, Zhang D, Manson K, Kim J, Boyer J, Weiner DB: Inclusion of Vpr accessory gene in a plasmid vaccine cocktail markedly reduces Nef vaccine effectiveness in vivo resulting in CD4 cell loss and increased viral loads in rhesus macaques. J Med Primatol 2002, 31:179-185.

185. Bouzar AB, Villet S, Morin T, Rea A, Genestier L, Guiguen F, Garnier C, Mornex JF, Narayan O, Chebloune Y: Simian immunodeficiency virus Vpr/ Vpx proteins kill bystander noninfected CD4+ T-lymphocytes by induction of apoptosis. Virology 2004, 326:47-56.

186. Moon HS, Yang JS: Role of HIV Vpr as a regulator of apoptosis and an effector on bystander cells. Mol Cells 2006, 21:7-20.
187. Azad AA: Could Nef and Vpr proteins contribute to disease progression by promoting depletion of bystander cells and prolonged survival of HIV-infected cells? Biochem Biophys Res Commun 2000, 267:677-685.

188. Groux H, Torpier G, Monte D, Mouton Y, Capron A, Ameisen JC: Activationinduced death by apoptosis in CD4+ T cells from human immunodeficiency virus-infected asymptomatic individuals. J Exp Med 1992, 175:331-340.

189. Meyaard L, Schuitemaker H, Miedema F: T-cell dysfunction in HIV infection: anergy due to defective antigen-presenting cell function? Immunol Today 1993, 14:161-164.

190. Yasuda J, Miyao T, Kamata M, Aida Y, Iwakura Y: T cell apoptosis causes peripheral T cell depletion in mice transgenic for the HIV-1 vpr gene. Virology 2001, 285:181-192.

191. Nishizawa M, Kamata M, Mojin T, Nakai Y, Aida Y: Induction of apoptosis by the Vpr protein of human immunodeficiency virus type 1 occurs independently of G(2) arrest of the cell cycle. Virology 2000, 276:16-26.

192. Li G, Park HU, Liang D, Zhao RY: Cell cycle G2/M arrest through an S phase-dependent mechanism by HIV-1 viral protein R. Retrovirology 2010, 7:59.

193. Muthumani K, Zhang D, Hwang DS, Kudchodkar S, Dayes NS, Desai BM, Malik AS, Yang JS, Chattergoon MA, Maguire HC Jr, Weiner DB: Adenovirus encoding HIV-1 Vpr activates caspase 9 and induces apoptotic cell death in both p53 positive and negative human tumor cell lines. Oncogene 2002, 21:4613-4625

194. Shostak LD, Ludlow J, Fisk J, Pursell S, Rimel BJ, Nguyen D, Rosenblatt JD, Planelles $\mathrm{V}$ : Roles of p53 and caspases in the induction of cell cycle arrest and apoptosis by HIV-1 vpr. Exp Cell Res 1999, 251:156-165.

195. Stewart SA, Poon B, Song JY, Chen IS: Human immunodeficiency virus type $1 \mathrm{vpr}$ induces apoptosis through caspase activation. J Virol 2000, 74:3105-3111.

196. Majumder B, Venkatachari NJ, Schafer EA, Janket ML, Ayyavoo V: Dendritic cells infected with vpr-positive human immunodeficiency virus type 1 induce CD8+ T-cell apoptosis via upregulation of tumor necrosis factor alpha. J Virol 2007, 81:7388-7399.

197. Richard J, Sindhu S, Pham TN, Belzile JP, Cohen EA: HIV-1 Vpr up-regulates expression of ligands for the activating NKG2D receptor and promotes NK cell-mediated killing. Blood 2010, 115:1354-1363.

198. Ward J, Davis Z, DeHart J, Zimmerman E, Bosque A, Brunetta E, Mavilio D, Planelles V, Barker E: HIV-1 Vpr triggers natural killer cell-mediated lysis of infected cells through activation of the ATR-mediated DNA damage response. PLoS Pathog 2009, 5:e1000613.

199. Hong HS, Bhatnagar N, Ballmaier M, Schubert U, Henklein P, Volgmann T, Heiken H, Schmidt RE, Meyer-Olson D: Exogenous HIV-1 Vpr disrupts IFNalpha response by plasmacytoid dendritic cells ( $\mathrm{pDCs}$ ) and subsequent pDC/NK interplay. Immunol Lett 2009, 125:100-104.

200. Majumder B, Venkatachari NJ, O'Leary S, Ayyavoo V: Infection with Vprpositive human immunodeficiency virus type 1 impairs NK cell function indirectly through cytokine dysregulation of infected target cells. J Virol 2008, 82:7189-7200.

201. Majumder B, Janket ML, Schafer EA, Schaubert $K$, Huang XL, Kan-Mitchell Rinaldo CR Jr, Ayyavoo V: Human immunodeficiency virus type $1 \mathrm{Vpr}$ impairs dendritic cell maturation and T-cell activation: implications for viral immune escape. J Virol 2005, 79:7990-8003.

202. Mariani R, Rasala BA, Rutter G, Wiegers K, Brandt SM, Krausslich HG, Landau NR: Mouse-human heterokaryons support efficient human immunodeficiency virus type 1 assembly. J Virol 2001, 75:3141-3151.

203. Muthumani K, Desai BM, Hwang DS, Choo AY, Laddy DJ, Thieu KP, Rao RG, Weiner DB: HIV-1 Vpr and anti-inflammatory activity. DNA Cell Biol 2004, 23:239-247.

204. Venkatachari NJ, Majumder B, Ayyavoo V: Human immunodeficiency virus (HIV) type $1 \mathrm{Vpr}$ induces differential regulation of $\mathrm{T}$ cell costimulatory molecules: direct effect of $\mathrm{Vpr}$ on $\mathrm{T}$ cell activation and immune function. Virology 2007, 358:347-356

205. Muthumani K, Hwang DS, Choo AY, Mayilvahanan S, Dayes NS, Thieu KP, Weiner DB: HIV-1 Vpr inhibits the maturation and activation of macrophages and dendritic cells in vitro. Int Immunol 2005, 17:103-116.

206. Muthumani K, Choo AY, Hwang DS, Dayes NS, Chattergoon M, Mayilvahanan S, Thieu KP, Buckley PT, Emmanuel J, Premkumar A Weiner DB: HIV-1 Viral protein-r (Vpr) protects against lethal superantigen challenge while maintaining homeostatic $T$ cell levels in vivo. Mol Ther 2005, 12:910-921 
207. Auphan N, DiDonato JA, Rosette C, Helmberg A, Karin M: Immunosuppression by glucocorticoids: inhibition of NF-kappa B activity through induction of I kappa B synthesis. Science 1995, 270:286-290.

208. Scheinman Rl, Cogswell PC, Lofquist AK, Baldwin AS, Jr: Role of transcriptional activation of I kappa B alpha in mediation of immunosuppression by glucocorticoids. Science 1995, 270:283-286.

209. Ayyavoo V, Mahboubi A, Mahalingam S, Ramalingam R, Kudchodkar S, Williams WV, Green DR, Weiner DB: HIV-1 Vpr suppresses immune activation and apoptosis through regulation of nuclear factor kappa $\mathrm{B}$. Nat Med 1997, 3:1117-1123.

210. Mirani M, Elenkov I, Volpi S, Hiroi N, Chrousos GP, Kino T: HIV-1 protein Vpr suppresses IL-12 production from human monocytes by enhancing glucocorticoid action: potential implications of Vpr coactivator activity for the innate and cellular immunity deficits observed in HIV-1 infection. J Immunol 2002, 169:6361-6368.

211. Muthumani K, Kudchodkar S, Papasavvas E, Montaner $L$, Weiner DB, Ayyavoo V: HIV-1 Vpr regulates expression of beta chemokines in human primary lymphocytes and macrophages. J Leukoc Biol 2000, 68:366-372.

212. Varin A, Decrion A, Sabbah E, Quivy V, Sire J, Van Lint C, Roques B, Aggarwal B, Herbein G: Synthetic Vpr protein activates activator protein1, c-Jun N-terminal kinase, and NF-kappaB and stimulates HIV-1 transcription in promonocytic cells and primary macrophages. $J$ Biol Chem 2005, 280:42557-42567.

213. Roux P, Alfieri C, Hrimech M, Cohen E, Tanner J: Activation of transcription factors NF-kappaB and NF-IL-6 by human immunodeficiency virus type 1 protein R (Vpr) induces interleukin-8 expression. J Virol 2000, 74:4658-4665.

214. Eckstein DA, Sherman MP, Penn ML, Chin PS, De Noronha CM, Greene WC, Goldsmith MA: HIV-1 Vpr enhances viral burden by facilitating infection of tissue macrophages but not nondividing CD4+ T cells. J Exp Med 2001, 194:1407-1419.

215. Lang SM, Weeger M, Stahl-Hennig C, Coulibaly C, Hunsmann G, Muller J, Muller-Hermelink H, Fuchs D, Wachter H, Daniel MM, et al: Importance of vpr for infection of rhesus monkeys with simian immunodeficiency virus. J Virol 1993, 67:902-912.

216. Tzitzivacos DB, Tiemessen CT, Stevens WS, Papathanasopoulos MA: Viral genetic determinants of nonprogressive HIV type 1 subtype $C$ infection in antiretroviral drug-naive children. AIDS Res Hum Retroviruses 2009, 25:1141-1148.

217. Jacquot G, Le Rouzic E, Maidou-Peindara P, Maizy M, Lefrere JJ, Daneluzzi V, Monteiro-Filho CM, Hong D, Planelles V, Morand-Joubert L, Benichou S: Characterization of the molecular determinants of primary HIV-1 Vpr proteins: impact of the Q65R and R77Q substitutions on Vpr functions. PLoS One 2009, 4:e7514.

218. Aquaro S, Svicher V Schols D, Pollicita M, Antinori A, Balzarini J, Perno CF: Mechanisms underlying activity of antiretroviral drugs in HIV-1-infected macrophages: new therapeutic strategies. J Leukoc Biol 2006, 80:1103-1110.

219. Dutta T, Agashe HB, Garg M, Balakrishnan P, Kabra M, Jain NK: Poly (propyleneimine) dendrimer based nanocontainers for targeting of efavirenz to human monocytes/macrophages in vitro. J Drug Target 2007, 15:89-98.

220. Vyas TK, Shah L, Amiji MM: Nanoparticulate drug carriers for delivery of HIV/AIDS therapy to viral reservoir sites. Expert Opin Drug Deliv 2006, 3:613-628.

221. Swingler S, Mann AM, Zhou J, Swingler C, Stevenson M: Apoptotic killing of HIV-1-infected macrophages is subverted by the viral envelope glycoprotein. PLoS Pathog 2007, 3:1281-1290.

222. Huang Y, Erdmann N, Peng H, Herek S, Davis JS, Luo X, Ikezu T, Zheng J: TRAIL-mediated apoptosis in HIV-1-infected macrophages is dependent on the inhibition of Akt-1 phosphorylation. J Immunol 2006, 177:2304-2313.

223. Chugh P, Bradel-Tretheway B, Monteiro-Filho CM, Planelles V, Maggirwar SB, Dewhurst S, Kim B: Akt inhibitors as an HIV-1 infected macrophagespecific anti-viral therapy. Retrovirology 2008, 5:11

224. Kapasi AA, Coscia SA, Pandya MP, Singhal PC: Morphine modulates HIV-1 gp160-induced murine macrophage and human monocyte apoptosis by disparate ways. J Neuroimmunol 2004, 148:86-96.

225. Li G, Bukrinsky M, Zhao RY: HIV-1 viral protein $R$ (Vpr) and its interactions with host cell. Curr HIV Res 2009, 7:178-183.
226. Liang D, Benko Z, Agbottah E, Bukrinsky M, Zhao RY: Anti-vpr activities of heat shock protein 27. Mol Med 2007, 13:229-239.

227. Iordanskiy S, Zhao Y, Dubrovsky L, lordanskaya T, Chen M, Liang D, Bukrinsky M: Heat shock protein 70 protects cells from cell cycle arrest and apoptosis induced by human immunodeficiency virus type 1 viral protein R. J Virol 2004, 78:9697-9704.

228. Iordanskiy S, Zhao Y, DiMarzio P, Agostini I, Dubrovsky L, Bukrinsky M: Heatshock protein 70 exerts opposing effects on Vpr-dependent and Vprindependent HIV-1 replication in macrophages. Blood 2004, 104:1867-1872.

229. Yedavalli VS, Shih HM, Chiang YP, Lu CY, Chang LY, Chen MY, Chuang CY, Dayton Al, Jeang KT, Huang LM: Human immunodeficiency virus type 1 Vpr interacts with antiapoptotic mitochondrial protein HAX-1. J Virol 2005, 79:13735-13746.

230. Gibellini D, Re MC, Ponti C, Vitone F, Bon I, Fabbri G, Grazia Di lasio M, Zauli G: HIV-1 Tat protein concomitantly down-regulates apical caspase10 and up-regulates c-FLIP in lymphoid T cells: a potential molecular mechanism to escape TRAIL cytotoxicity. J Cell Physiol 2005, 203:547-556.

231. Haffar OK, Smithgall MD, Popov S, Ulrich P, Bruce AG, Nadler SG, Cerami A Bukrinsky MI: CNI-H0294, a nuclear importation inhibitor of the human immunodeficiency virus type 1 genome, abrogates virus replication in infected activated peripheral blood mononuclear cells. Antimicrob Agents Chemother 1998, 42:1133-1138.

232. Suzuki T, Yamamoto N, Nonaka M, Hashimoto Y, Matsuda G, Takeshima SN, Matsuyama M, Igarashi T, Miura T, Tanaka $R$, et al: Inhibition of human immunodeficiency virus type 1 (HIV-1) nuclear import via Vpr-Importin alpha interactions as a novel HIV-1 therapy. Biochem Biophys Res Commun 2009, 380:838-843

233. Paxton W, Connor Rl, Landau NR: Incorporation of Vpr into human immunodeficiency virus type 1 virions: requirement for the p6 region of gag and mutational analysis. J Virol 1993, 67:7229-7237.

234. Yao XJ, Kobinger G, Dandache S, Rougeau N, Cohen E: HIV-1 Vprchloramphenicol acetyltransferase fusion proteins: sequence requirement for virion incorporation and analysis of antiviral effect. Gene Ther 1999, 6:1590-1599.

235. Ao Z, Yu Z, Wang L, Zheng Y, Yao X: Vpr14-88-Apobec3G fusion protein is efficiently incorporated into Vif-positive HIV-1 particles and inhibits viral infection. PLOS ONE 2008, 3:e1995.

236. Mariani R, Chen D, Schrofelbauer B, Navarro F, Konig R, Bollman B, Munk C, Nymark-McMahon $H$, Landau NR: Species-specific exclusion of APOBEC3G from HIV-1 virions by Vif. Cell 2003, 114:21-31.

237. Sheehy AM, Gaddis NC, Choi JD, Malim MH: Isolation of a human gene that inhibits HIV-1 infection and is suppressed by the viral Vif protein. Nature 2002, 418:646-650.

238. Stewart SA, Poon B, Jowett JB, Xie Y, Chen IS: Lentiviral delivery of HIV-1 Vpr protein induces apoptosis in transformed cells. Proc Natl Acad Sci USA 1999, 96:12039-12043.

239. Shimura M, Tanaka Y, Nakamura S, Minemoto Y, Yamashita K, Hatake K, Takaku F, Ishizaka Y: Micronuclei formation and aneuploidy induced by Vpr, an accessory gene of human immunodeficiency virus type 1. Faseb J 1999, 13:621-637

doi:10.1186/1742-4690-8-25

Cite this article as: Kogan and Rappaport: HIV-1 Accessory Protein Vpr: Relevance in the pathogenesis of HIV and potential for therapeutic intervention. Retrovirology 2011 8:25. 